\title{
Multicatalytic Hybrid Materials for Biocatalytic and Chemoenzymatic Cascades-Strategies for Multicatalyst (Enzyme) Co-Immobilization
}

\author{
Aldo Araújo da Trindade Júnior ${ }^{1}$, Yan Ferraz Ximenes Ladeira ${ }^{2}$, Alexandre da Silva França ${ }^{3}$, \\ Rodrigo Octavio Mendonça Alves de Souza ${ }^{3}$, Adolfo Henrique Moraes ${ }^{2}$ (D) , Robert Wojcieszak ${ }^{4}$ (D), \\ Ivaldo Itabaiana, Jr. ${ }^{1,4, *(\mathbb{D})}$ and Amanda Silva de Miranda ${ }^{2, *}$
}

Citation: Júnior, A.A.d.T.; Ladeira, Y.F.X.; França, A.d.S.; Souza R.O.M.A.d.; Moraes, A.H.; Wojcieszak, R.; Itabaiana, I., Jr.; Miranda, A.S.d. Multicatalytic Hybrid Materials for Biocatalytic and Chemoenzymatic Cascades-Strategies for Multicatalyst (Enzyme) Co-Immobilization. Catalysts 2021, 11, 936. https:// doi.org/10.3390/catal11080936

Academic Editor: Zheng Guo

Received: 6 July 2021

Accepted: 30 July 2021

Published: 31 July 2021

Publisher's Note: MDPI stays neutral with regard to jurisdictional claims in published maps and institutional affiliations.

Copyright: (c) 2021 by the authors. Licensee MDPI, Basel, Switzerland. This article is an open access article distributed under the terms and conditions of the Creative Commons Attribution (CC BY) license (https:// creativecommons.org/licenses/by/ $4.0 /)$
1 Department of Biochemical Engineering, School of Chemistry, Federal University of Rio de Janeiro, Rio de Janeiro 21941-910, Brazil; aldoaraujot@gmail.com

2 Departmento de Química, ICEX, Universidade Federal de Minas Gerais, Belo Horizonte 31270-901, Brazil; yan.ximenes.012@gmail.com (Y.F.X.L.); adolfohmoraes@ufmg.br (A.H.M.)

3 Biocatalysis and Organic Synthesis Group, Chemistry Institute, Federal University of Rio de Janeiro, Rio de Janeiro 21941-919, Brazil; alexandre_ifrj@yahoo.com.br (A.d.S.F.); souzarod@gmail.com (R.O.M.A.d.S.)

4 University of Lille, CNRS, Centrale Lille, UMR 8181-UCCS-Unité de Catalyse et Chimie du Solide, F-59000 Lille, France; robert.wojcieszak@univ-lille.fr

* Correspondence: ivaldo@eq.ufrj.br (I.I.J.); a.s.miranda@hotmail.com (A.S.d.M.)

\begin{abstract}
During recent decades, the use of enzymes or chemoenzymatic cascades for organic chemistry has gained much importance in fundamental and industrial research. Moreover, several enzymatic and chemoenzymatic reactions have also served in green and sustainable manufacturing processes especially in fine chemicals, pharmaceutical, and flavor/fragrance industries. Unfortunately, only a few processes have been applied at industrial scale because of the low stabilities of enzymes along with the problematic processes of their recovery and reuse. Immobilization and co-immobilization offer an ideal solution to these problems. This review gives an overview of all the pathways for enzyme immobilization and their use in integrated enzymatic and chemoenzymatic processes in cascade or in a one-pot concomitant execution. We place emphasis on the factors that must be considered to understand the process of immobilization. A better understanding of this fundamental process is an essential tool not only in the choice of the best route of immobilization but also in the understanding of their catalytic activity.
\end{abstract}

Keywords: enzymes; immobilization; chemoenzymatic cascades; biocatalysis; nanomaterials

\section{Introduction}

Biocatalysis has been recognized as a valuable tool for the development of more sustainable methods in organic synthesis [1]. In the synthesis of fine chemicals, the remarkable chemo-, regio-, and stereoselectivity of enzymes and their ability to operate under mild conditions might not only allow for the development of alternatives to some methods based on traditional non-enzymatic catalysts but also broaden the repertoire of synthetic routes to a given compound to include greener (chemo)enzymatic routes [2,3]. Moreover, biocatalysts are biodegradable and obtained from renewable sources and can convert renewable biomass to commodity chemicals, thus playing a key role in the transition of a petroleum-based economy to a biobased economy [4].

The development of recombinant DNA technology in the 1970s, as well as advances in protein engineering and bioinformatics in recent decades, have made a huge contribution to expanding the use of enzymes in organic synthesis by providing tools to overcome limitations traditionally associated with biocatalysis [4-6]. Prospection and production of enzymes has become easier, thus widening the repertoire of available biocatalysts, and methods for optimization of enzymatic properties, such as scope, activity, selectivity, and 
stability have been developed. Nevertheless, the use of enzymes in industrial processes for the obtaining of fine chemicals remains challenging. An important aspect of the development of a cost-effective and industrially suitable biocatalytic process relies on the recycling and recovery of the biocatalyst [7]. This issue has been addressed by immobilization. Immobilization not only makes enzymes recoverable and reusable but also improves their tolerance to organic solvents, by suppressing aggregation and denaturation caused by unfolding, and enables them to be used in continuous flow reactors [4,8,9]. Although immobilization usually leads to a decrease in enzymatic activity, this is compensated by reusability and stability, thus leading to higher productivity [4].

Cascade reactions are considered an important approach for the development of greener processes in organic synthesis. Performing two or more concurrent or consecutive reactions in a one-pot fashion without isolation of intermediates may lead to more selective reactions due to fast removing of unstable intermediates, increase yields by shifting equilibrium in reversible reactions, lead to overall higher atom economy, reduce the generation of waste and consumption of resources and result in economic and environmental benefits $[10,11]$. Advantages of biocatalysis can be brought together with benefits of cascade reactions through the combination of enzymes in multi-enzymatic multistep processes [10,12-17] as well as the combination of enzymes and non-enzymatic catalysts, such as metals, in chemoenzymatic cascades $[13,18,19]$. Although multi-enzymatic catalysis is facilitated by compatibility and usually similar operational conditions between enzymes, chemoenzymatic cascades are more challenging due to incompatibility issues. On the other hand, chemoenzymatic cascades offer opportunities to combine the strengths of both biocatalysis and the chemocatalysis field, thus broaden possibilities and bringing versatility [20-23].

In the current above-described scenario, co-immobilization of multi(bio)catalysts in a single support to give materials with multicatalytic function offers the traditional advantages associated with immobilization itself, such as improvement of catalysts stability and recovery, as well as additional benefits that have the potential to improve cascade efficiency and overcome typical challenges inherent to the development of cascade processes. For instance, co-immobilization can bring different (bio)catalysts in close proximity, thus avoiding diffusion of intermediates to the reaction media bulk, in a similar way to natural biochemical cascades, and allows for synergetic effects between catalysts. Conversely, coimmobilization of enzymes and chemocatalysts can offer compartmentalization strategies to overcome incompatibility issues [15,16,24-26]. Co-immobilization of (bio)catalysts is a promising but also challenging field whose advances might come from multidisciplinary efforts involving areas such as chemistry, biology, and material sciences. Herein we describe immobilization techniques and strategies for co-immobilization of multibiocatalysts as well as the combination of enzymes and chemocatalysts to provide multicatalytic hybrid materials. The basis of most common immobilization techniques is covered and strategies for obtaining multicatalytic materials designed to promote cascade reactions towards the synthesis of fine chemicals are highlighted.

\section{Co-Immobilization of Enzymes}

\subsection{Co-Immobilization of Enzymes into Solid Supports}

Enzymes are an intelligent and interesting option to be used as catalyst in chemical reactions, mainly due to their high activity and unique selectivity. In the recent years, the use of enzymes has become more popular in chemical and food processing [27], being the efficiency of catalytic activity dependent on reaction parameters such as $\mathrm{pH}$, solvent and temperature, as well as the type of enzyme studied. Enzymes can be used in free or immobilized form for biocatalytic process [28]. Unfortunately, immobilized enzymes still suffer from higher prices compared to the free form, despite the stability and activity improvements that can be achieved by immobilization techniques [29].

Since 1916, immobilization of biocatalyst into solid supports had been growing intensely, allowing its use in several biocatalytic processes and generating a great scien- 
tific impact [30]. Since the early ages of enzyme immobilization, several immobilization techniques have been reported with different enzyme types and functions [31-38]. Immobilization of enzymes into support provides convenient handling and separation of the biocatalyst from reaction medium. Furthermore, it often increases enzyme stability towards denaturation by autolysis, denaturation by organic solvents or by heat, as well as boosting the enzyme activity in some cases, which results from the creation of a microenvironment in which the enzyme acts, in contrast to the bulk solution [39,40]. Additionally, these supported enzymes can be used for several applications such as biomedical [41], biosensors [42], analytical determinations [43], biocatalyzed reactions [44], analytical, and preparative separations [45].

Immobilization of enzymes can be defined as the attachment of the target molecules to a support resulting in reduced or complete loss of their mobility. In most cases, immobilization can lead to partial or total loss of biocatalytic activity. The decrease in activity can arise from changes in protein conformation after immobilization, structural modifications on the protein during immobilization, or changes in the protein microenvironment resulting from its interaction with the support [46]. To retain a maximum enzymatic activity, the origins of these effects need to be understood, especially those related to the structural organization of the protein on the immobilization surface [47].

It is widely believed that the loss in activity is due to attachment of proteins on the immobilization support through several amino acid residues [48]. This results in a random orientation of the immobilized biomolecule and in increased structural deformation due to multipoint attachment. Several researchers have explored ways to orient proteins on surfaces, such that orderly organization, single point attachment and accessibility of the active site (or binding site) are possible [49].

The preservation of native structure requires careful determination of attachment sites most resistant to conformational change prior to immobilization. It was claimed that such conformationally oriented immobilization strategy would lead to good steric accessibility of the active binding site and to increased overall stability of the protein. Thus, for example, sites that are localized far from the binding site, such as carbohydrate side chains of glycoproteins, or cysteine residues that can be introduced by site-directed mutagenesis at desired locations, are good candidates for immobilization [49]. Most random immobilizations occur through exposed residues such as lysine, which are usually located on the surfaces of the proteins and are not involved in the binding site. However, there is a possibility of multipoint attachments resulting in loss of activity, due to conformational changes or obstruction of the binding site of the immobilized protein [50].

In 2013, Sheldon and Pelt [9] proposed the categorization of enzyme immobilization techniques into three main categories: adsorption, covalent bonding and entrapment. The first category is a physical method dependent on adsorption forces and electrostatic interactions between the enzyme and a matrix. Immobilization by covalent bond involves formation of a covalent bond between the terminal residues of the biomolecule and a functional group on the support, while encapsulation or microencapsulation methods refers to the entrapment of an enzyme in polymeric matrices [9,51].

The immobilization techniques cited herein present some advantages and drawbacks. Adsorption is usually effective, cheap and simple but frequently reversible, while covalent attachments are durable and effective, but expensive and can reduce the enzyme performance in some cases. Encapsulation can present diffusional problems and reduce mass-transfer values, which is inherent in membrane reactor-confinement [11]. The nature of the support can vary from biopolymers, such as cellulose and chitosan, to synthetic resins, such as zeolite or silica. However, no specific method or support is suitable for all enzymes and applications due to differences in composition and chemical characteristics of enzymes, specific characteristics of the developed process, and the different properties of substrates and products [52].

Different matrices and materials have been used for the co-immobilization of two or more biocatalyst for synthetic purposes. Some of them are summarized in Table 1. 
Table 1. Matrices used for co-immobilization of enzymes for synthetic purposes. GDH = glycerol dehydrogenase, $\mathrm{PDOR}=1,3-$ propanodiol oxidoreductase, $\mathrm{GDHt}=$ glycerol-dehydratase, $\mathrm{LDH}=$ lactate dehydrogenase, $\mathrm{GlDH}=$ glutamate dehydrogenase, $\mathrm{SDR}=$ short-chain dehydrogenase/reductase from Thermus theruophiles, $\mathrm{G}-\mathrm{DH}=$ glucose dehydrogenase, $\mathrm{XDH}=\mathrm{xylose}$ dehydrogenase, $\mathrm{ADH}=$ alcohol dehydrogenase, $\mathrm{FDH}=$ formate dehydrogenase, $\mathrm{FaldDH}=$ formaldehyde dehydrogenase, $\mathrm{ScP}=$ sucrose phosphorylase, $\mathrm{CbP}=$ cellobiose phosphorylase, $\mathrm{CdP}=$ cellodexrtin phosphorylase, $\omega \mathrm{TA}=\omega$-transaminase, $\mathrm{L}$ $\mathrm{AlaDH}=\mathrm{L}$-alanine dehydrogenase, $\mathrm{CAL}-\mathrm{B}=$ Candida antarctica $\mathrm{B}$ lipase, $\beta$-Gal $=\beta$-galactosidase, $\mathrm{PDH}=$ polyol dehydrogenase, $\mathrm{CHMO}=$ cyclohexanone monooxygenase, $\mathrm{CelA}=$ cellulase, $\beta-\mathrm{Gl}=\beta$-glucosidase, $\mathrm{GOx}=$ glucose oxidase, $\alpha-\mathrm{AMA}=\alpha-$ amylase, $\mathrm{MAM}=$ maltogenic amylase, $\mathrm{HRP}=$ horseradish peroxidase, $\mathrm{GA}=$ glucoamylase, $\mathrm{MCF}=$ mesocellular siliceous foam, $\mathrm{AKR}=$ aldo-keto reductase, $\mathrm{D}-\mathrm{HA}=\mathrm{D}$-hydantoinase, $\mathrm{D}-\mathrm{CA}=\mathrm{D}$-carboamylase, $\mathrm{DKR}=$ dynamic kinetic resolution, PaoABC $=$ periplasmic aldehyde oxidase, $\mathrm{CAT}=$ catalase, $\beta$-FFA $=\beta$-fructofuranosidase, $\mathrm{MOF}=$ metal-organic framework, $\mathrm{CA}=$ carbonic anhydrase, $\mathrm{AGE}=\mathrm{N}$-acyl-D-lucosamine-2-epimerase, $\mathrm{NAL}=\mathrm{N}$-acetylneuraminate lyase, $\mathrm{CSS}=\mathrm{CMP}$-syalic acid synthetase, $\mathrm{CMP}=$ cytidine monophosphate, $\mathrm{BDH}=2,3$-butanediol dehydrogenase, $\mathrm{P} 450=$ monooxygenase from cytochrome P450, NHS = N-hydroxy-succinimide.

\begin{tabular}{|c|c|c|c|}
\hline Matrix & Immobilization Method & Enzymes & Applications \\
\hline $\mathrm{TiO}_{2}$ nanoparticles & adsorption & $\mathrm{GDH} / \mathrm{PDOR} / \mathrm{GDHt}$ & $\begin{array}{l}\text { Conversion of glycerol to } \\
\text { 1,3-propanediol [53] }\end{array}$ \\
\hline Amberlite-XAD7 & adsorption & $\mathrm{LDH} / \mathrm{GlDH}$ & $\begin{array}{l}\text { Reductive amination of } \\
\alpha \text {-ketoglutarate [54] }\end{array}$ \\
\hline Silica gel & adsorption & SDR/G-DH & $\begin{array}{l}\text { Reduction of ethyl } \\
\text { benzoylformate to ethyl } \\
\text { (S)-mandelate [55] }\end{array}$ \\
\hline $\begin{array}{l}\text { Silica-coated magnetite } \\
\text { nanoparticle }\end{array}$ & adsorption & $\mathrm{XADH} / \mathrm{ADH}$ & $\begin{array}{l}\text { Oxidation of xylose to xylonic } \\
\text { acid }[56,57]\end{array}$ \\
\hline Cellulose membrane & adsorption & FDH/FaldDH/ADH & Methanol synthesis from $\mathrm{CO}_{2}[58]$ \\
\hline $\begin{array}{l}\text { Anioinic macroporous } \\
\text { poly)methyl methacrilate } \\
\text { particles (ReliSorb SP400) }\end{array}$ & adsorption & $\mathrm{ScP} / \mathrm{CbP} / \mathrm{CdP}$ & $\begin{array}{c}\text { Synthesis of } \\
\text { cello-oligosaccharides [59] }\end{array}$ \\
\hline $\begin{array}{l}\text { Anioinic macroporous } \\
\text { poly)methyl methacrilate } \\
\text { particles (ReliSorb SP400) }\end{array}$ & adsorption & P450/G-DH & C-H hydroxylation reactions [60] \\
\hline $\mathrm{Ni}^{2+}$-containing agarose beads & $\begin{array}{l}\text { Metal coordination, } \\
\text { covalent bond }\end{array}$ & $\mathrm{ADH} / \mathrm{GIDH}$ & $\begin{array}{l}\text { Alcohol oxidation, ketone } \\
\text { reduction [61] }\end{array}$ \\
\hline $\begin{array}{c}\mathrm{Co}^{2+} \text {-containing agarose } \\
\text { microbeads }\end{array}$ & Metal coordination & $\mathrm{ADH} / \omega \mathrm{TA} / \mathrm{L}-\mathrm{AlaDH}$ & $\begin{array}{l}\text { Alcohol oxidation/reductive } \\
\text { amination cascade [62] }\end{array}$ \\
\hline Octyl-agarose beads & Adsorption, ion exchange & CAL-B/ $\beta-$ Gal & Ester hydrolysis [63] \\
\hline $\begin{array}{l}\text { Amino-functionalized } \\
\text { methacrylic polymer }\end{array}$ & Covalent bond & $\mathrm{PDH} / \mathrm{CHMO}$ & $\begin{array}{c}\text { Alcohol oxidation/Bayer-Villiger } \\
\text { reaction cascade [64] }\end{array}$ \\
\hline Amino-functionalized agarose & Covalent bond & CHMO/G-DH & Bayer-Villiger reaction [65] \\
\hline Epoxy-functionalized agarose & Covalent bond & P450/G-DH & C-H hydroxylation [66] \\
\hline $\begin{array}{l}\text { Amino-functionalized } \\
\text { iron-based magnetic } \\
\text { nanoparticles }\end{array}$ & Covalent bond & $\mathrm{CelA} / \beta-\mathrm{Gl} / \mathrm{GOx} / \mathrm{HRP}$ & $\begin{array}{c}\text { Carboxymethylcellulose } \\
\text { hydrolysis [67] }\end{array}$ \\
\hline $\begin{array}{l}\text { Amino-functionalized } \\
\text { iron-based magnetic } \\
\text { nanoparticles }\end{array}$ & $\begin{array}{c}\text { Covalent } \\
\text { bond/Combi-CLEAs }\end{array}$ & $\alpha$-AMA/MAM & Starch conversion to maltose [68] \\
\hline $\begin{array}{l}\text { Amino-functionalized } \\
\text { silver dendrites }\end{array}$ & Covalent bond & $\mathrm{DOx} / \mathrm{GA}$ & $\begin{array}{c}\text { Starch hydrolysis/glucose } \\
\text { oxidation cascade [69] }\end{array}$ \\
\hline Amino-functionalized MCF & Covalent bond & AKR/G-DH & $\beta$-ketoester reduction [70] \\
\hline Alginate & Entrapment & AKR/G-DH & $\beta$-ketoester reduction [70] \\
\hline
\end{tabular}


Table 1. Cont.

\begin{tabular}{|c|c|c|c|}
\hline Matrix & Immobilization Method & Enzymes & Applications \\
\hline Alginate & Entrapment & $\mathrm{LacA} / \mathrm{CalA} / \beta-\mathrm{Gl}$ & $\begin{array}{l}\text { Conversion of lignocellulosic } \\
\text { biomass to saccharides [71] }\end{array}$ \\
\hline Epoxy-functionalized silica & Covalent bond & LDH/G-DH & Pyruvate reduction to lactate [72] \\
\hline $\begin{array}{l}\text { Hydrazide-functionalized } \\
\text { methacrylate polymer }\end{array}$ & Covalent bond & GOx/HRP & Glucose oxidation [73] \\
\hline $\begin{array}{c}\text { Amino-functionalized } \\
\text { polystyrene nanoparticles }\end{array}$ & Covalent bond & GOx/HRP & Glucose oxidation [74] \\
\hline $\begin{array}{l}\text { Amino-functionalized } \\
\text { silica nanoparticles }\end{array}$ & Covalent bond, protein fusion & $\mathrm{BDH} / \mathrm{FDH}$ & Ketone reduction [75] \\
\hline $\begin{array}{l}\text { NHS-magnetic } \\
\text { sepharose beads }\end{array}$ & Covalent bond, protein fusion & $\mathrm{P} 450 / \mathrm{PdR} / \mathrm{PdX}$ & Hydroxylation reactions [76] \\
\hline- & Combi-CLEA & GOx/HRP & Glucose oxidation [77] \\
\hline- & Combi-CLEA & ADH/G-DH & Ketone reduction [78] \\
\hline Alginate, chitosan & encapsulation & D-HA/D-CA & $\begin{array}{l}\text { Hydantoin DKR and } \\
\text { decarboxylation [79] }\end{array}$ \\
\hline Silicious hydrogel & encapsulation & PaoABC/CAT & Aldehyde oxidation [80] \\
\hline Silicious hydrogel & encapsulation & $\beta$-FFA/GOx & $\begin{array}{l}\text { Production of lactosucrose from } \\
\text { sucrose and lactose }[81,82]\end{array}$ \\
\hline ZIF-8 (MOF) & encapsulation & $\mathrm{ADH} / \mathrm{LDH}$ & Pyruvate reduction to lactate [83] \\
\hline ZIF-8 (MOF) & encapsulation & $\mathrm{FDH} / \mathrm{GDH}$ & Methanol synthesis from $\mathrm{CO}_{2}[84]$ \\
\hline ZIF-8 (MOF) & encapsulation & $\mathrm{CA} / \mathrm{FDH} / \mathrm{GDH}$ & Formate synthesis from $\mathrm{CO}_{2}$ [85] \\
\hline $\begin{array}{l}\text { Polyurethane hollow } \\
\text { nanofibers }\end{array}$ & encapsulation & FDH/FaldDH/ADH/GIDH & Methanol synthesis from $\mathrm{CO}_{2}$ [86] \\
\hline Polymersome & encapsulation & AGE/NAL/CSS & $\begin{array}{c}\text { Synthesis of } \\
\text { CMP-N-acetylneuramic acid [87] }\end{array}$ \\
\hline
\end{tabular}

\subsubsection{Co-Immobilization of Enzymes through Adsorption}

Adsorption is the simplest and oldest method of immobilizing enzymes onto supports. This technique is based on physical adsorption (e.g., hydrogen bonding, hydrophobic interactions, van der Waals force, and their combinations) of the enzyme onto the surface of water-insoluble carriers [88]. Adsorbed enzymes are protected from aggregation, proteolysis and interaction with hydrophobic interfaces. This method became popular for enzyme immobilization because of its simplicity and efficiency [89,90]. Carriers in this segment must have mechanical and chemical resistance, be insoluble in water and have a high surface area in order to be eligible for adsorption immobilization protocols [91]. Among the several supports developed so far, mesoporous silicates are probably the most used [92]. In 1992 , the discovery of silicates group with a precise pore size distribution, pore sizes in the range of 20-300 $\AA$, and amorphous silica surfaces, offered the possibility of adsorbing or entrapping molecules within their pores [93]. Since the first developments, these supports have improved the field of enzyme immobilization [51]. Mesoporous silicates provide a sheltered protected environment in which reactions with its substrates can proceed [94]. The usage of porous silica allows superficial modifications with the introduction of different functional groups such as alkyl, amino, carboxyl, thiol, among others aiming to enable repulsion or electrostatic attraction between the silicate support and the biological molecule of interest [95-98].

Natural and modified activated carbon-based materials have been explored as carrier for enzyme immobilization. Activated carbon-based materials showing high surface area ranging between 600 and $1000 \mathrm{~m}^{2} \cdot \mathrm{g}^{-1}$ and pore volumes between 300 and $1000 \AA$ A have 
been described to be ideal in improving enzyme activity upon their immobilization [99]. The particle size of the material and their porosity are also important parameters that allow for different strategies in immobilization method. Depending on the size of the pores as well as their arrangement, the accessibility to the enzymes can be affected. In 2002, Novozymes started commercialization of Lipozyme ${ }^{\circledR}$ TL IM, a robust cost-effective lipase from Thermomyces lanuginosus immobilized on silicate (300-1000 $\mu \mathrm{m}$ particle size). The large particle size distribution enabled the use of this biocatalyst in a continuous flow reactor and the hydrophilic carrier retains the required water needed to maintain enzyme activity in a continuous process. On the other hand, the surface area of $1071 \mathrm{~m}^{2} \cdot \mathrm{g}^{-1}$, pore volume of $1.05 \mathrm{~cm}^{3} \cdot \mathrm{g}^{-1}$ and pore diameter of $3.85 \mathrm{~nm}$ favor excellent enzyme adsorption [100]. Agostinelli and co-workers [101] have proposed an ingenious immobilization process based on polyketone polymer as a support for enzyme immobilization. The immobilization procedure was carried out exclusively via a large number of hydrogen bonds between the - $\mathrm{NH}$ groups of the polypeptide chain and the carbonyl groups of the polymer. A high binding capacity and extraordinary stable immobilization was observed. Moreover, activity measurements showed that immobilized enzymes retain their fully catalytic characteristics [102].

Even though some adsorption strategies allow efficient immobilization, it can lead to structural modifications on the biocatalyst [51,103,104]. Thyparambil and co-workers [103] reported that loss in $\alpha$-helix content of silica-adsorbed lysozyme was related to a decrease in enzyme activity.

An alternative approach is the use of ionic exchange methodology that is also proposed as a tool to solve some enzyme stability problems [105]. This method is a multipoint process in which the enzyme interacts with the support only when a high number of ionic interactions to compensate for the ionic strength of the media is established between the protein and the polymer. Polyethylenimine (PEI) is perhaps one of the most studied ionic polymer used on this strategy [106-109]. Modification of immobilized enzymes with PEI has been proposed as part of a new strategy for enzyme co-immobilization. The possibility of using ionic polymers for physical crosslinking of the enzyme molecules immobilized via physical interactions and to prevent enzyme leakage during operation has been recently discussed. Unfortunately, this was studied in an enzyme biocatalyst modified with PEI for other goal. The limitation of this methodology may be the release of many enzymes into the reactor during operation, decreasing the activity of the enzyme and contaminating the product [110].

\subsubsection{Co-Immobilization of Enzymes through Covalent Bonds}

An interesting method of enzyme immobilization can be achieved by the formation of covalent bonds between the biocatalyst and the matrix. Covalent bonds commonly provide the strongest linkages between enzyme and support, compared with other types of enzyme immobilization methods and it occurs between functional groups on the surface of support and amino acid residue on the surface of the enzyme (Table 2).

Table 2. Different methods for covalent binding of enzymes to supports [35,111-114].

\begin{tabular}{cc}
\hline Reaction & Support-Enzyme Linkage \\
\hline Diazotization & Support- $=\mathrm{N}-$ Enzyme \\
\cline { 2 - 2 } Alkylation and arylation & Support- $\mathrm{C}_{2}-\mathrm{N}-$ Enzyme \\
\cline { 2 - 2 } & Support- $\mathrm{C}_{2}-\mathrm{S}-$ Enzyme \\
\hline Schiff's base formation & Support- $=\mathrm{C}=$ Enzyme \\
\hline
\end{tabular}


Table 2. Cont.

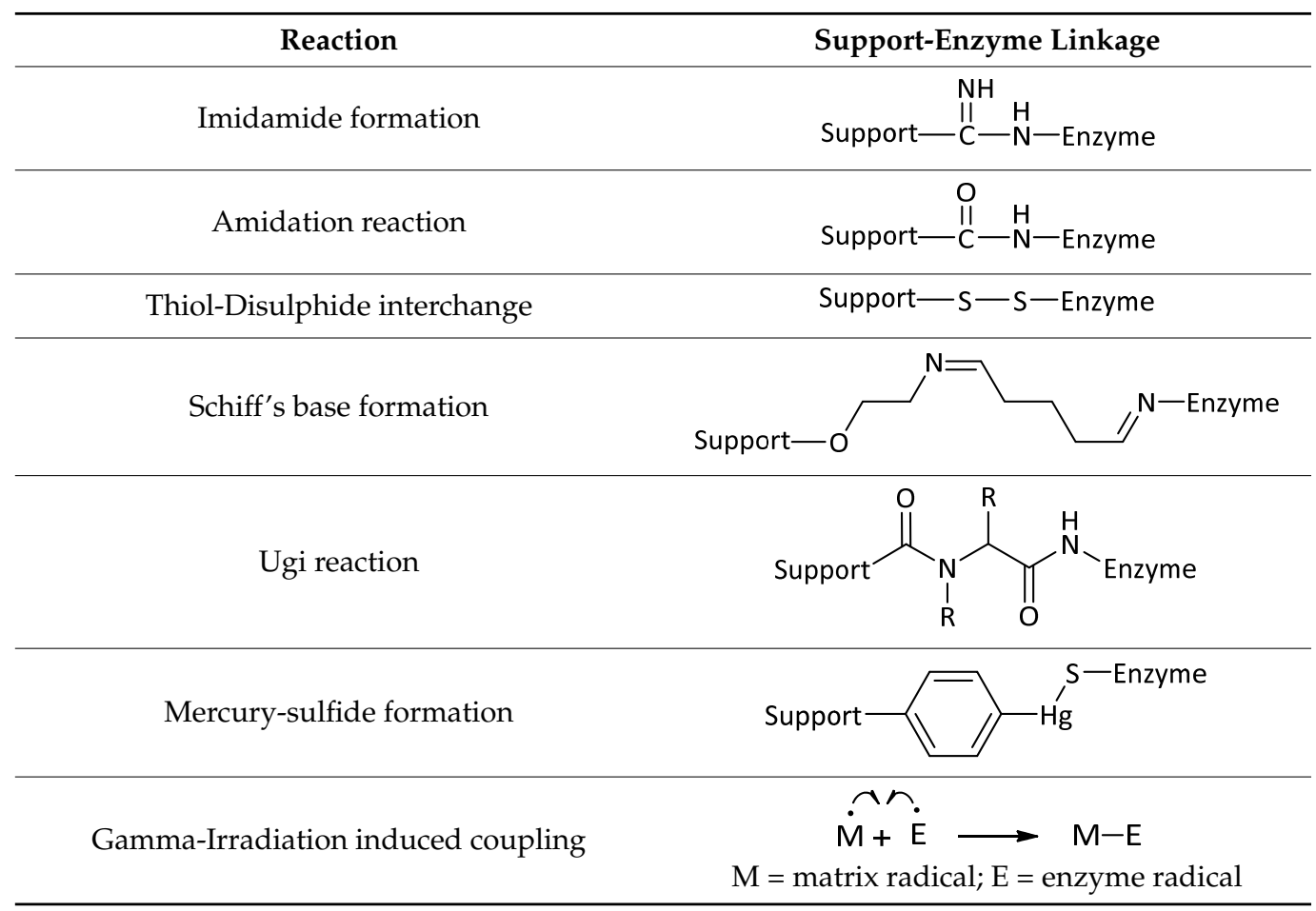

The different possibilities of interactions allow the investigation of different matrices and its functional groups, such as synthetic polymers and biopolymers, with the great advantage of localization of enzyme on support surface [115].

Polymeric materials are commonly used for controlled drug delivery and as support for biomolecules. Modification of the surface of enzymes, using synthetic biocompatible polymers such as poly(ethylene glycol) (PEG) [8], is a well-established tool to increase the functional stability of the enzyme [101]. Polymers containing hydroxyl, amino, amide, and carboxyl groups have been used for enzyme immobilization, and, because of their advantages, polymer supports have gained more attention for applications in biosensors and biochips in recent years [36,113].

Biopolymers or biopolymer blends are also of considerable importance on immobilization and have been widely used as supports for biocatalyst reactions as they are mainly water-insoluble polysaccharides [116-118]. These materials form an inert aqueous gel characterized by high gel strength, even at low concentration. Moreover, due to their chemical characteristics they may be prepared to bind enzymes in a reversible or irreversible way. In addition, they are relatively cheap and environmentally friendly. Likewise, with the usage of bifunctional reagents, it is possible to create cross-links that strengthen their structure, increasing their thermal and mechanical resistance [119].

Among all biopolymers, cellulose is one of the most important biomass resources due to its abundance. On the other hand, with the rapid progression of nanotechnology, "nanocellulose" has emerged as a material with properties such as distinct morphology and geometrical dimensions, high specific surface area and mechanical robustness which make it greatly useful as support for enzyme immobilization [120,121]. The low toxicity, great renewability and biodegradability of cellulose and nanocellulose matrix have made them commonplace in industrial applications. Similarly, various enzymes, such as laccase [122], cyclodextrin glucanotransferase [123], glucose oxidase, Penicillin G acylase [124], and lipases from Candida rugosa [125] have been immobilized onto diverse forms of cellulose.

Chitosan is a biomolecule derivative from chitin, this copolymer of glucosamine and $\mathrm{N}$-acetyl glucosamine is obtained via the $\mathrm{N}$-deacetylation of chitin [126]. Chitin is another naturally abundant polymer, which is transformed into chitosan via enzymatic deacetyla- 
tion or chemical treatment [127]. In fact, advances in nanocarrier area show different forms to fashion a chitosan support [128], since despite numerous advantages of chitosan, the use of the biopolymer in a blend is more advantageous because the pure biopolymer is not sufficiently robust for extensive use under industrial settings due to bead softness and sensitiveness to $\mathrm{pH}$, particularly to acidic media [129]. Researchers have already used a hybrid biopolymer composite of chitosan and chitin nanowhiskers as support material. This blend presents advantages such as mechanical strength, biocompatibility and non-toxicity, as well as the high concentrations of surface amino and hydroxyl groups that can facilitate the crosslinking to the enzyme [130].

The materials and general methods mentioned above have been exploited for coimmobilization of two or more enzymes in a single solid support for enzymatic onepot cascade reactions $[12,15,16,26,131-133]$. Co-immobilization of enzymes is challenging since the co-immobilization method must be suitable for the different enzymes to be immobilized and control of the localization of different enzymes and activity ratio might be required for an efficient cascade. On the other hand, co-immobilization has been suggested to increase the efficiency of cascade reactions through a "microdomain effect" by creating specific microenvironments in which intermediates are "pseudo-trapped" by reversible interactions so that their dilution into the reaction bulky is prevented. The result is an increased effective concentration of both intermediates and enzymes and improved transport between different sites, thus leading to more efficient cascade reactions [15].

The simplest strategy for co-immobilizing enzymes is random co-immobilization, which can be achieved by mixing enzyme solutions with supports [26]. Random co-immobilization of enzymes by adsorption for cascade reactions has been reported [26,53,54,134,135]. For instance, Liu and co-workers [55] described the co-immobilization of a short-chain dehydrogenase/reductase and a NAD $(\mathrm{P})$-dependent glucose dehydrogenase on silica gel for the preparation of ethyl (S)-mandelate from ethyl benzoyl formate. In this cascade reaction, the short-chain dehydrogenase/reductase catalyzes the enantioselective reduction of a prochiral carbonyl group at the expense of NADPH as a reducing cofactor, which is then converted to NADP+. NADPH is then regenerated by oxidation of glucose catalyzed by a glucose dehydrogenase so that this expansive cofactor is allowed to be used in catalytic amounts, while the readily available, non-expensive glucose is used as the final reducing agent. Using the dual-enzyme catalyst, the reaction could be performed in $1.5 \mathrm{~h}$ with $72 \%$ conversion and $>99 \%$ enantiomeric excess. The dual-enzyme catalyst showed improved thermostability in comparison to the free enzymes and could retain $60 \%$ of its activity after being reused 30 times at $55^{\circ} \mathrm{C}$. Similarly, co-immobilization of xylose dehydrogenase and an ADH for cofactor regeneration on magnetite-silica core-shell nanoparticles has been reported and employed in the obtaining of xylonic acid from xylose [56,57]. In comparison to the free enzymes, the dual-enzyme catalyst was found to be more effective in a broader range of temperature $\left(15-35^{\circ} \mathrm{C}\right)$ and $\mathrm{pH}(6-8)$. Moreover, the dual catalyst showed a half-life four times higher and retained $65 \%$ of its initial activity after five consecutive reaction cycles.

More sophisticated co-immobilization strategies using adsorption as immobilization have been recently reported to achieve controlled distribution and localization of enzymes [16,54,58,136,137]. For instance, Zhong and co-workers [59] reported the use of protein fusion to obtain three phosphorylases bearing cationic modules composed of 58 amino acids containing multiple histidine residues. Because of the high affinity of the module to anionic support, a uniform co-immobilization of the enzymes could be achieved, so that the activity ratio of the enzymes in the as-obtained multicatalytic material could be controlled. The support used in this work, namely ReliSorb SP400, consists of macroporous polymethacrylate particles with 700-200 $\mu \mathrm{m}$ diameter and pores with 80-100 nm diameter so that the pores were larger and therefore accessible to all the enzymes used (11-14 nm). The anionic character of the support results from the presence of sulfonate groups on its surface. The multi-enzymatic catalyst was employed in a cascade reaction for the production of cello-oligosaccharides from sucrose and glucose. Noteworthy, a proper activity ratio between the enzymes is a crucial feature in this cascade to avoid the obtaining 
of oligosaccharides with a high degree of polymerization, which precipitates in reaction media. A different strategy to promote uniform and homogeneous co-immobilization to achieve colocalization of two enzymes was reported by Rocha-Martín and co-workers [61]. They described the immobilization of an ADH and a GDH as the second enzyme for cofactor regeneration in agarose beads bearing $\mathrm{Ni}^{2+}$ sites and glyoxyl groups. The ADH was first immobilized while the GDH was then sequentially immobilized in the presence of imidazole, which competes with the enzyme for $\mathrm{Ni}^{2+}$ sites. This procedure allowed for colocalization of enzymes in the same bead and resulted in a more efficient cascade in comparison to dual catalysts without an optimal distribution of enzymes. Interestingly, colocalization of three enzymes in the same bead of a support was achieved by VelascoLozano and co-workers [62] by co-immobilizing His-tagged enzymes ADH, L-AlaDH, and $\omega$-TA ( $\omega$-transaminase) into agarose microbeads featuring $\mathrm{Co}^{2+}$ sites. Experiments showed that the three enzymes could be localized at the outer surface of the porous beads with $4 \mathrm{~nm}$ between the enzymes. The multi-enzymatic catalyst was employed in a redox neutral cascade for the synthesis of amino alcohols from diols. In this process, ADH catalyzes the oxidation of a terminal hydroxyl group of a diol to give a hydroxyl aldehyde at the expense of $\mathrm{NAD}^{+}$. The hydroxyl aldehyde is then converted to an amino alcohol in a reaction catalyzed by a $\omega$-TA that also converts L-alanine, the amine donor, to pyruvate. The cycle is completed by conversion of pyruvate to L-alanine, which also regenerates $\mathrm{NAD}^{+}$. Noteworthy, cofactor recycling was found to be more efficient when the cascade was performed with the multi-enzymatic catalyst in comparison to the use of the three enzymes immobilized in different beads, thus suggesting a beneficial effect of enzyme colocalization.

A challenging feature of co-immobilization is the use of the same conditions for immobilizing different enzymes in the same support, which are usually not the optimal condition for each enzyme. In addition, co-immobilization usually has the disadvantage that the stability of the multi-enzymatic catalyst is limited to the stability of the least stable enzyme. Peirce and co-workers [63] reported a strategy to overcome these issues, which was applied to the co-immobilization of lipase B of Candida Antarctica (CAL-B) and $\beta$-galactosidase from Aspergillus oryzae ( $\beta$-gal) through adsorption on octyl-agarose beads. First, CAL-B is incubated with the support for immobilization through adsorption. The octyl-agarose beads with adsorbed CAL-B are then treated with a solution of polyethyleneimine (PEI) to give PEI-coated beads, on which $\beta$-gal enzymes are then immobilized through ion exchange. The introduction of a PEI-coating allowed for the immobilization of $\beta$-gal under different conditions to those used for co-immobilization of CAL-B. Importantly, the protective PEI-layer also allowed for reloading of $\beta$-gal without affecting CAL-B, so that the dual catalyst could be "regenerated" instead of being discharged after deactivation of the least stable enzyme, thus improving reusability. Experiments showed that $\beta$-gal could be desorbed from the dual catalyst after use by treatment with $\mathrm{NaCl}$ solution without affecting CAL-B activity and loading and new $\beta$-gal could be adsorbed onto the PEI-coated agarose beads containing adsorbed CAL-B.

Co-immobilization of enzymes through covalent binding to supports have been reported to build multi-enzymatic catalyst for cascade reactions [64]. A simple method for covalent co-immobilization of a Bayer-Villiger monooxygenase (BVMO) and a glucose dehydrogenase (DGH) on amino-functionalized agarose beads through amide bonds was reported by Delgove and co-workers [65]. Co-immobilization was achieved by incubating both enzymes simultaneously with the support to promote ionic absorption, followed by the addition of EDC to promote amide bond formation between the enzymes and the support and the addition of $\mathrm{NaCl}$ to remove enzymes that were not covalently bound to the matrix. The dual-enzyme catalyst was employed in the conversion of 3,3,5-trimethylcyclohexanone to the corresponding $\varepsilon$-caprolactone through a biocatalyzed Bayer-Villiger reaction, while glucose dehydrogenase was used for cofactor (NADPH) regeneration. The conditions used for the co-immobilization procedure were determined as a compromise between the optimum conditions for separate immobilization of each enzyme since high concentrations of EDC were found to improve BVMO immobilization 
but also to deactivate GDH. The resulting dual-enzyme catalyst presented a BVMO/GDH dehydrogenase ration of 1:0.5. Notably, the reaction times for the co-immobilized enzymes were found to be shorter in comparison to the separately immobilized enzymes, which was ascribed to a better cofactor diffusion between the enzymes in the former. Importantly, the dual-enzyme catalyst also led to better recyclability and better overall conversion over 15 cycles when compared to free and separately immobilized enzymes. Simultaneous covalent co-immobilization of enzymes has also been reported as a simple method obtaining a multi-enzymatic catalyst employed in the hydrolysis of carboxymethylcellulose [67]. For this purpose, cellulose, $\beta$-glucosidase, glucose oxidase, and horseradish peroxidase enzymes were co-immobilized onto the surface of amino-functionalized magnetic nanoparticles using the glutaraldehyde method. Co-immobilization led to some loss of activity but resulted in a multifunctional nanobiocatalyst with improved thermostability that could also be easily handled and separated from reaction media due to the magnetic properties of the nanoparticles. Examples of simultaneous or simple sequential covalent co-immobilization of enzymes for cascade reaction include co-immobilization of glucose oxidase and glucoamylase on silver dendrites hierarchical nanostructures for the obtaining of gluconic acid from starch [69], among others [26,70,72,73,138].

Strategies for controlling the localization of different covalently co-immobilized enzymes have been reported. For instance, proximity between two different enzymes in dual-enzyme catalysts has been achieved by obtaining protein conjugates [74] or combiCLEAs [68] and further immobilizing them in into solid supports covalently. A sophisticated strategy was reported by Tan and co-workers [76] to co-immobilize monooxygenase of Pseudomonas putida (P450cam) together with P. putida ferredoxin (PdX) and ferredoxin reductase $(\mathrm{PdR})$. This multi-enzymatic system catalyzes reactions that are attractive for organic syntheses, such as enantioselective epoxidation of alkenes, hydroxylations, and decarboxylation of fatty acids to produce alkenes. Co-immobilization, however, is challenging, since the enzymes must be aligned and in close proximity but also maintain mobility. This goal could be achieved through protein fusion with subunits of the proliferating cell nuclear antigen (PCNA) from Sulfolobus solfataricus. PCNA is composed of subunits PCNA1, PCNA2, and PCNA3. By covalently immobilizing PCNA2 on a solid support and add PCNA1 fused to PdR and PdX and PCNA3 fused to P450cam, the proper localization of the three enzymes could be achieved through PCNA assembly due to the affinity between the three subunits.

Co-immobilization of enzymes into solid carriers for the synthesis of fine chemicals through cascade reactions is a developing field. Despite the so far reported methods and strategies, such as those mentioned above, new strategies and cascade reactions using multicatalytic catalysts in preparative scales are still to be developed.

\subsection{Cross-Linked Enzymes Aggregates-CLEAs}

The carrier-free enzyme immobilization is an alternative to the carrier-bound enzyme methodologies. The carrier-free immobilization dispenses the need to use expensive matrices and avoids the volumetric yield reduction caused by the presence of such materials. One of the most used and promising carrier-free enzyme immobilization methodologies is the cross-linked enzyme aggregates (CLEAs). CLEAs are generated through covalent bond formation between free enzymes. Usually, CLEAs are relatively easy to produce and show a reasonable recovery rate, which impacts their technological application costs [139]. The first production of CLEAs was reported by Cao et al. [140], who developed Penicillin Acylase CLEAs. The CLEAs production protocols are generally simple, and the first and one of the most critical steps is enzyme precipitation via the addition of precipitation agents as salts, organic solvents, and specific polymers. For this reason, CLEAs use is becoming popular even in biopharmaceuticals production [141]. The most significant difficulty for CLEAs application is the limited aggregates diffusion in solution and its recovery process. Those limitations can be diminished using some additives, which will be further described. In Figure 1, we showed a simplified protocol for CLEAs production. 


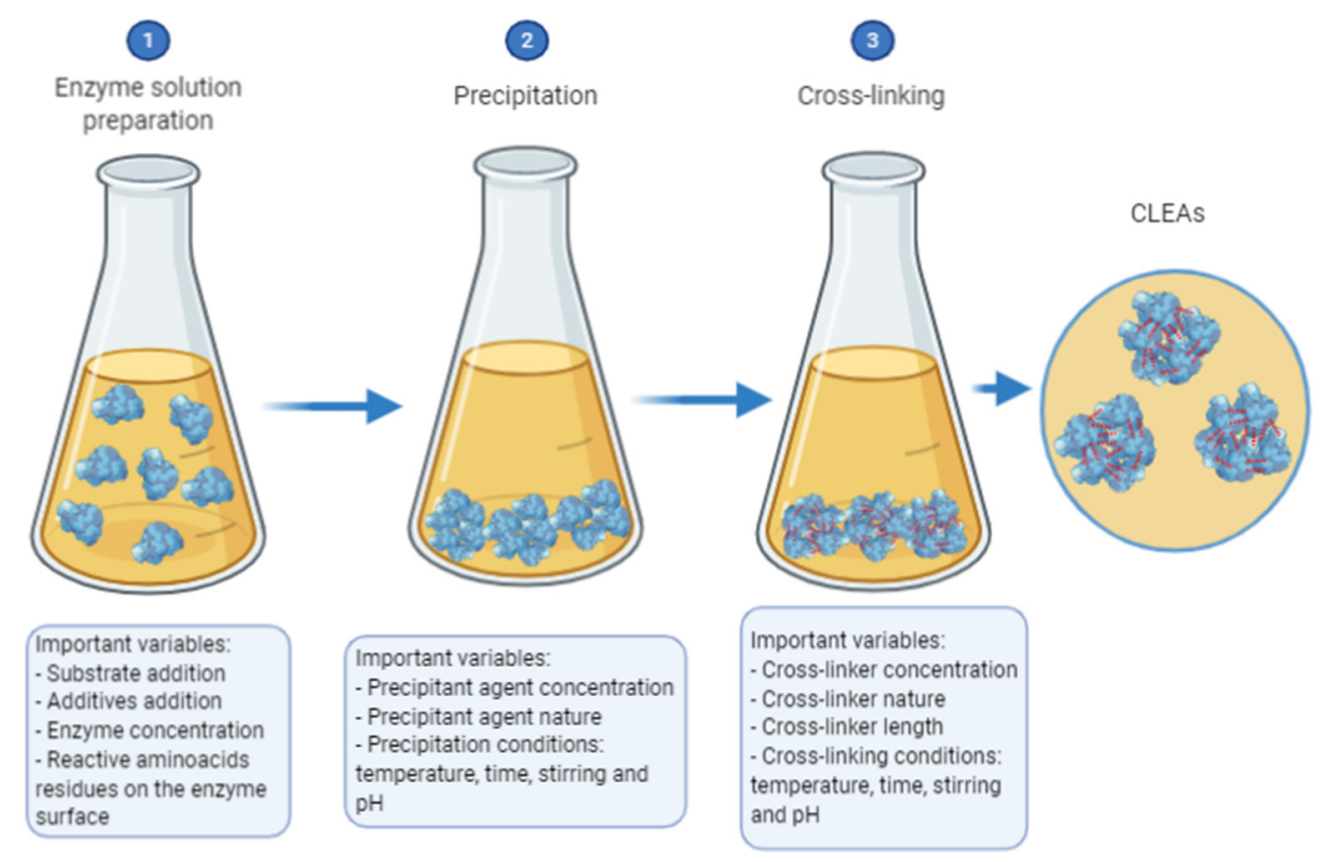

Figure 1. Simplified protocol for CLEAs production. The cross-linkers are represented by the lines in red. Adapted from reference [125].

Despite being a very empirical process, where many conditions are enzyme-specific, a resumed description of protocols can be organized. CLEAs production can be summarized in the following steps: enzyme production, enzyme solution preparation, precipitation, crosslinking generation, CLEAs characterization.

Enzyme production: Interesting enzymes could be isolated from natural organisms or produced via heterologous expression in a different organism host. With the development of DNA recombinant technology and genetic-engineered hosts, as modified versions of $E$. Coli, enzymes' recombinant production became a prominent strategy for biotechnology application of such natural catalysts. Many protocols are available, and they can be optimized for each enzyme. Different protocols for recombinant enzyme production can be found in a variety of reviews [142,143]. Purified enzymes are obtained using different chromatographic techniques. The most common ones are affinity chromatography (usually $\mathrm{Ni}^{2+}$ affinity chromatography), size-exclusion chromatography, and ion-exchange chromatography [142].

Enzyme solution preparation: The enzyme solution can be constituted of a purified enzyme or cell lysate. It is essential to prepare the enzyme solution to enable and favors the downstream steps: precipitation and crosslinking. Hence some variables are important to be considered, such as enzyme concentration, which is recommended to be between 2 and $100 \mathrm{mg} / \mathrm{mL}$, and the presence of reactive amino acid residues on enzyme surface to a crosslinking formation such as lysine [139]. Another important feature is the addition of additives that can perform different functions in CLEAs production. They can improve enzyme activity, thermostability, $\mathrm{pH}$ stability, solvent stability, immobilization yield, selectivity, and diffusion rate.

Some additives can be used as co-feeders to prevent protein inactivation due to excessive cross-links formation or to enhance crosslinking formation when the enzyme has a low number of reactive residues. Bovine serum albumin (BSA) [144] and soy protein [145] are examples of additives. Polymers, such as PEI [146], chitosan [147], dextrin [148] and xanthan [148], and detergents, such as X100 [149], tween 80 [149], and SDS [149], among other substances, have also being used as additives. The diversity of additives, together with their variety of functions, gives CLEA's production and technological applications many possibilities. 
Recently, promising protocols were developed to facilitate CLEAs recovery after each reaction by co-immobilizing them on magnetic nanoparticles. Then, the co-immobilized CLEAs can be easily isolated from the reaction solution by applying an external magnetic field $[150,151]$. Another proposed innovation is the addition of porous-making agents, such as starch, to mitigate intra-particles diffusion limitations [152]. Another interesting methodology to enhance CLEAs activity is called bioimprinting, in which a substrate, substrate-analog, cofactor, or cofactor-analog molecule is added to the initial enzyme solution inducing the bound-enzyme conformation. The presence of ligands stabilizes active enzyme conformation over the crosslinking formation and can be removed by washing [139,153]. Diaz-Vidal et al. used olvanil as a bioimprint molecule on the production of Candida antarctica lipase B (CAL-B) CLEAs. By doing so, they enhanced the enzyme conversion rate 1.6 times over the CAL-B-CLEA [9].

Enzyme precipitation: Precipitation is carried out by adding precipitation agents to the enzyme solution. The precipitation agents shall precipitate the enzymes without causing denaturation or other substantial structural changes. The best precipitation agents can be selected by performing a screening study with precipitation agents and conditions [151]. The most used precipitation agents are salts [149], (for example, ammonium sulfate, ammonium chloride, and sodium sulfate), organic solvents (for example, acetone [141], tert-butyl alcohol [145], dimethoxyethane [145], ethanol [151], isopropanol [152]), and specific polymers [151] (for example, polyethylene glycol, chitosan, and polyethyleneimine). Experimental parameters often used to analyze the precipitation process success are precipitation ratio (the mass of the precipitated enzyme/mass of the original enzyme sample), structural and activity conservation over precipitation, evaluated by measuring the enzyme activity before and after the precipitation process by resuspending enzymes in buffer solution.

Crosslinking generation: the covalent-bound aggregates are generated by adding chemical crosslinking agents in the enzyme precipitates. The most used crosslinking agents are directed towards amides (glutaraldehyde, polyethyleneimine, diepoxides [154]) and carbonyls groups (when treated with carbodiimide [155]). Glutaraldehyde is the first-choice and most characterized crosslinking agent [114]. In addition to varying the crosslinking agents, screening for other experimental parameters such as crosslinking agent concentration, $\mathrm{pH}$, crosslinker size, temperature, and reaction time can change the observed cross-link outcomes reactions. Those related experimental variations can impact CLEAs thermo- and organic solvent stability, reusability, and specificity. Considering the complexity of factors that influence the crosslinking step efficiency, Goetze et al. [156] successfully applied response surface methodology (RSM) to analyze some parameters (enzyme concentration, glutaraldehyde concentration, and reaction time) to establish the optimal CLEAs formation conditions.

Characterization of enzyme aggregates: Many physical-chemical properties of CLEAs are evaluated during the different steps described above and used to classify experimental variations that can be performed to optimize CLEAs production. The most important ones are enzyme activity, thermal, $\mathrm{pH}$, and organic solvent stability; the recovered activity, calculated with Equation (1) [150], the immobilization yield, defined as the ratio between the amount of enzyme immobilized and total enzyme amount in the initial enzyme solution [152], reusability, and morphology.

$$
\text { Recovered activity }(\%):\left(\frac{\text { Total CLEA/s activity }}{\text { Total free enzyme activity }}\right) \times 100
$$

CLEA's surface morphology can be characterized through electronic scanning microscopy (SEM) [152] and atomic force microscopy (AFM) [157]. Fourier transform infrared spectroscopy (FTIR) can be used to analyze the efficiency of bounds formation in CLEAs [158], to verify the presence of functional groups for covalent bond formation between enzymes and functionalized magnetic nanoparticles [150] as well as identify the presence of some bounds in magnetic nanoparticles used as additives in CLEAs [159]. 
Solid-state nuclear magnetic resonance (NMR) spectroscopy is a promising technique that can describe changes in the secondary and tertiary structure of enzymes in the aggregates, which would be crucial information on CLEAs characterization. However, as far as we know, there is no publication exploiting this valuable resource, which shows new possibilities of CLEAs research improvement.

Co-immobilization by Crosslinking: Two or more different enzymes can be coimmobilized via CLEAs methodology. Such aggregates, named combi-CLEAs, are very useful in cascade enzymatic reactions. Combining multiple enzymes in a single CLEA can bring advantages such as stability enhancement compared to isolated enzymes, optimized mass transfer due to enzyme colocalization, fast intermediate consumption, and a high recovery rate [26]. The same protocols mentioned above for single enzyme CLEAs production can be applied to multiple enzymes co-immobilization via crosslinking. Combi-CLEAs protocols are case-specific, and some empirical factors need to be optimized as the relative concentration ratio of different enzymes and the crosslinking strategy [160]. Zhang et al. co-immobilized horseradish peroxidase (HRP), glucose oxidase (GOx), and Concanavalin A (ConA) using CLEAs methodology. In this study, ConA was used as a molecular glue to promote aggregation before the crosslinking step promoted by glutaraldehyde, as shown in Figure 2 [77]. The substrate uptake by the synthesized Combi-CLEAs improved due to the natural affinity of glucose to ConA, which reduced the glucose oxidase's Michaelis constant $\left(K_{\mathrm{m}}\right)$ [161], i.e., the substrate concentration required for the enzyme-catalyzed reaction to reach a rate corresponding to the half of the maximum reaction rate value. Moreover, it was observed a faster intermediate consumption by HPR, the second enzyme in cascade reaction, and consequently, a higher overall activity of combi-CLEAs was obtained. Yang et al. [162] reported the co-immobilization of monoamine oxidase and putrescine oxidase through CLEAs methodology using two different strategies: (i) crosslinking the two separated enzymes (combi-CLEAs); and (ii) crosslinking the two enzymes fused using molecular biology strategies (monoamine oxidase and putrescine oxidase-CLEAs-MAPO). They compared the efficiency of both strategies to identify biogenic amines in fermented foods. The combi-CLEAs exhibited a higher thermostability and yield than CLEAs-MAPO. Additionally, Combi-CLEAs showed a notable enhancement in thermostability compared to free enzymes, which could be a good feature for commercial kits to detect biogenic amines due to the extended biocatalyst half-life. Hu et al. applied the combi-CLEAs methodology to improve the efficiency of reactions involving cofactor recycling by coimmobilizing the ketoreductase (KRED) with glucose dehydrogenase (GDH) via CLEAs to enantioselectively reduce the prochiral ketone with KRED and regenerate the cofactor using GDH [78].

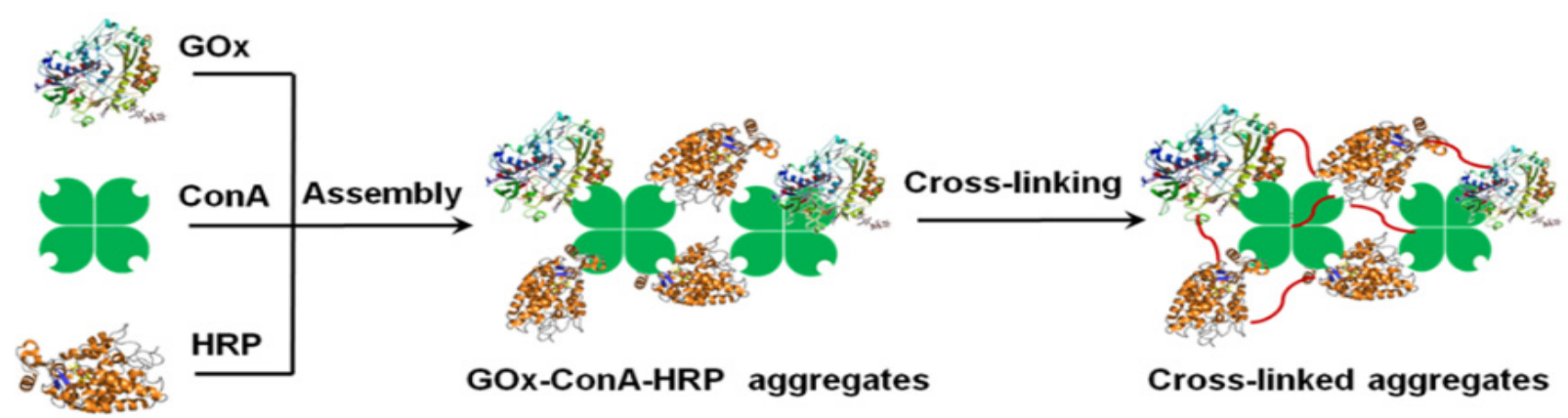

Figure 2. Illustration combi-CLEAs preparation using glucose oxidase, GOx, horseradish peroxidase HRP, ConA as glue protein and glutaraldehyde as crosslinker [77]. Reprinted with permission from [77]. Copyright (2016) America Chemical Society.

\subsection{Enzyme Co-Immobilization by Encapsulation}

The enzyme encapsulation method consists of the enzyme aggregation within a 3D matrix, while substrates and products should be able to be transported into and out of the membrane, by mass transfer [79]. One of the potentials of encapsulation is a physical 
inhibition of enzymatic denaturation due to heating, dehydration, or changes in the ionic strength of the solution [163]. These assignments still can be improved according to the chosen immobilization matrix, whereas the interaction with the enzyme can improve the catalytic stability and turn the system more advantageous. Among several matrices applied on encapsulation technology, the (bio) polymers capable of forming a gel, as well as nanofibers have been successfully applied in several reactions in organic synthesis, especially when there is a need to use organic solvents, high temperatures, and coupling of different biocatalysts in cascade reaction.

In these strategies, enzymes can be associated with the polymer through in situ gelling techniques, coprecipitation, and still be associated with chemical and heterogeneous catalysts, which makes it possible to be carried out in a one-pot approach.

\subsubsection{Gel Encapsulation}

Aranaz and co-workers [79] investigated the production of D-p-hydroxyphenylglycine (D-p-HPG), a precursor of amoxicillin synthesis, from D, L-hydroxyphenyl hydantoin (D, L-HPH), in the so-called "Hydantoinase process" (Figure 3), which is a potential producer of optically pure amines from a wide range of $\mathrm{D}, \mathrm{L}-5$-monosubstituted hydantoins. The crude cell extract from over-expressed Agrobacterium radiobacter has been encapsulated by two different methods: one-step procedure (V-I), in which the sodium alginate solution and the crude cell extract were directly poured into a solution containing chitosan and calcium; in two-step procedure (V-II), calcium-alginate capsules were coated with chitosan. For both biocatalysts, the highest yield of D-p-HPG has been obtained with an enzymatic load of $2 \mathrm{mg} / \mathrm{mL}$ of protein in the alginate solution, when compared to the production in the presence of free enzymes. Moreover, $100 \%$ of conversion on D-p-HPG was achieved when stirring increased to $100 \mathrm{rpm}$ for both biocatalysts. However, for values below $100 \mathrm{rpm}$, the V-I biocatalyst reached higher percentages of synthesis, since due to its preparation method it presents a less dense membrane structure. For $\mathrm{pH}$, the biocatalyst V-I showed a maximum production between $\mathrm{pH}$ values of 7.8 to 8.4 , while for catalyst V-II it was 8.5. When compared to the free extract, whose optimum value is 7.4, the immobilization of the catalysts led to the reaction at a more alkaline $\mathrm{pH}$, which favors the racemization of L-HPH to D-HPH. Regarding the reuse of biocatalysts, V-I was reused 5 times without any loss of activity. For V-II, this value was 4 times.

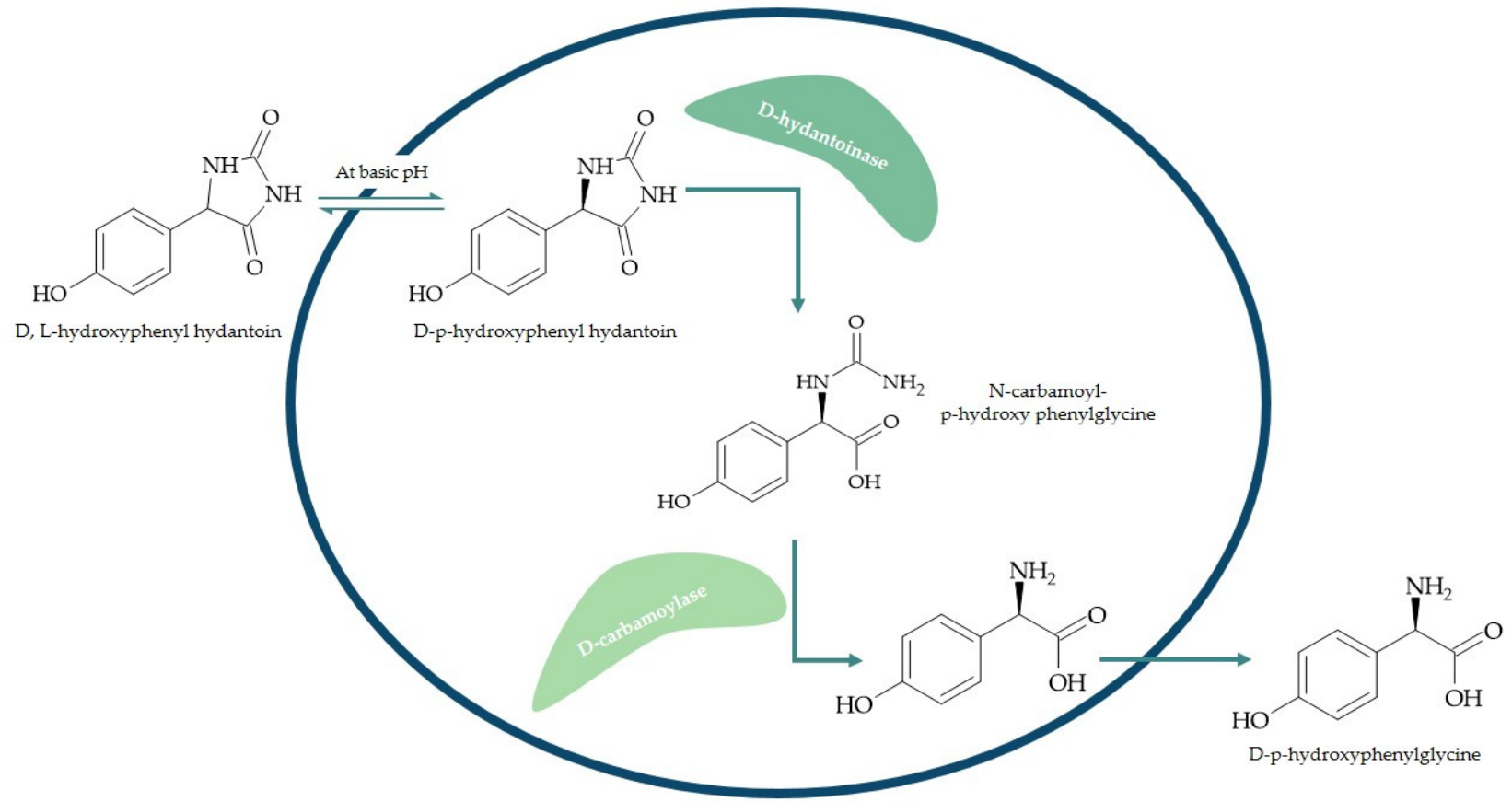

Figure 3. Hydantoinase process developed by Aranaz et al., 2015 [79]. 
Another cascade reaction application using gel encapsulation was reported by Mckenna and co-workers [80], which provides the production of 2,5-furandicarboxylic acid (FDCA) from 5-hydroxylmethylfurfural (HMF), a product of dehydration of lignocellulose. In a previous work by the group [164], a step-by-step reaction was used: first, under the presence of catalase, galactose oxidase $\mathrm{M}_{3-5}$ variant $\left(\mathrm{GOaseM}_{3-5}\right)$ catalyzes the oxidation of HMF to 2,5-diformylfuran (DFF), followed by the addition of periplasmic aldehyde oxidase $A B C$ (PaoABC) for double oxidation from DFF to FDCA, passing through the intermediate 5-formylfuran-2-carboxylic acid (FFCA). For the conversion of HMF to FDCA to be carried out in a continuous one-pot reaction (Figure 4a), there was the addition of the radish peroxidase enzyme (HPR), known to increase the activity of GOase. First, the best condition for obtaining DFF by the action of the $\mathrm{GOaseM}_{3-5}, \mathrm{HPR}$, and catalase set was identified, reaching a conversion of $91 \%$. The second step was to use this condition to choose the best concentration of PaoABC for the conversion of HMF to FDCA, which resulted in a conversion of FDCA. The last step consisted of choosing ways to immobilize the enzymes PaoABC and catalase to facilitate their reuse. Different forms of gel encapsulation were tested for PaoABC, while using CLEA immobilization for catalase. The best result for encapsulation was found using polyethyleneimine (PEI) as a matrix, which enabled a conversion from DFF to FDCA (in $90 \mathrm{~min}$ ) close to that of free PaoABC (in $60 \mathrm{~min}$ ). Then, they proceeded to an immobilization formulation of PaoABC and catalase (Figure $4 \mathrm{~b}$ ). When only the encapsulated PaoABC was used, there was a great decrease in the production of FDCA. When an encapsulation was performed for both enzymes, they could be reused three times, with conversion close to $70 \%$; encapsulation of PaoABC and CLEA-Catalase showed a $20 \%$ conversion in the first cycle, which makes it a poor strategy. The best result was obtained when CLEA-Catalase was combined with the already encapsulated PaoABC, which meant that the biocatalysts could be reused 14 times without loss of production, using $200 \mathrm{mM}$ DFF solution as a substrate. However, no study was carried out integrating the oxidation of HMF to DFF, by free GOaseM $_{3-5}$ and HRP, and oxidation of DFF to FDCA, with the immobilized PaoABC and catalase.
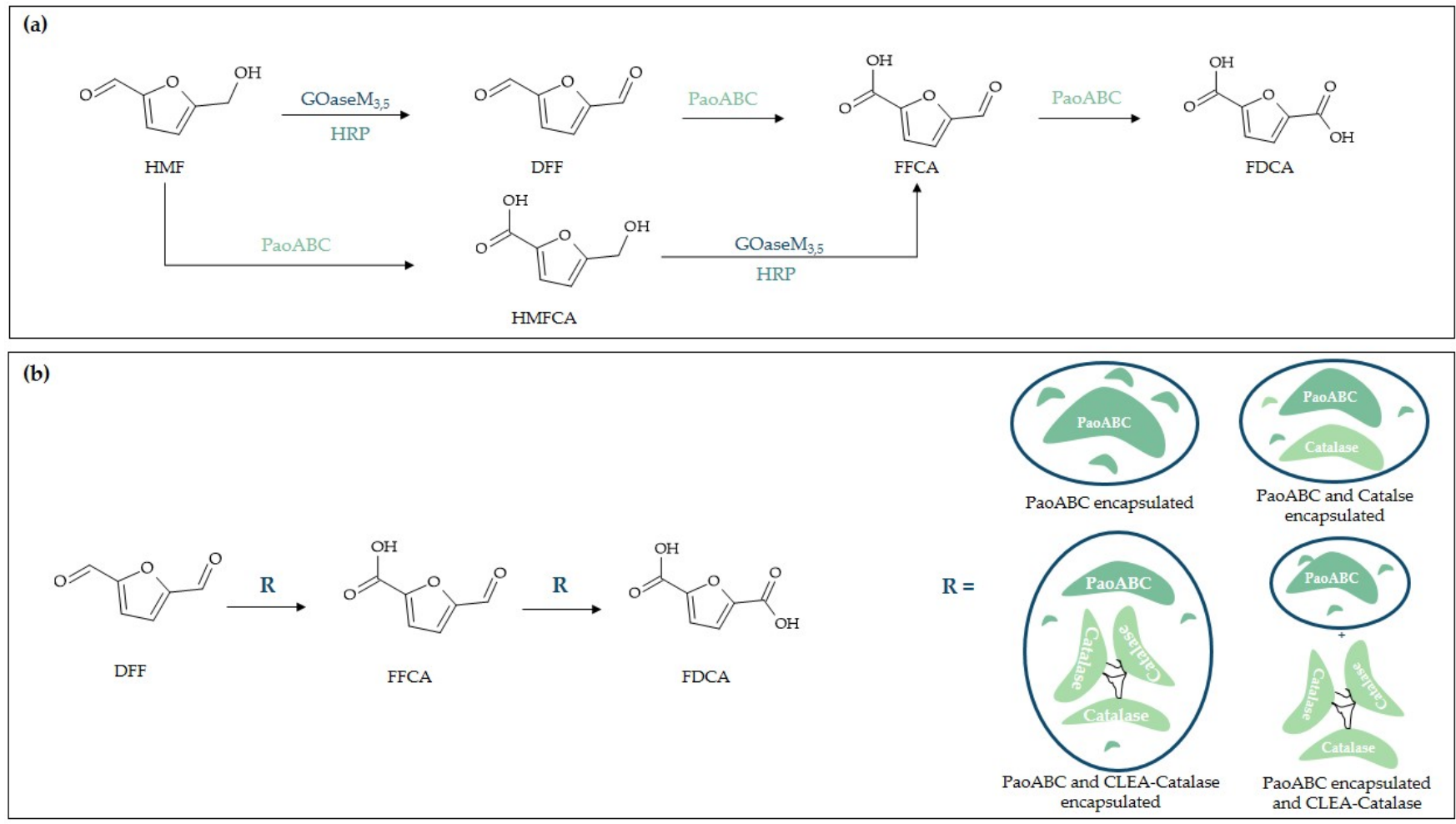

Figure 4. (a) One-Pot continuous (GOaseM3,5, HRP, PaoABC and catalase-non-immobilized enzymes) and (b) DFF oxidation to FDCA (PaoABC and catalase immobilized). DFF = 2,5-diformylfuran, FDAC = 2,5-furandicarboxylic acid, $\mathrm{HMF}=$ 5-hydroxymethylfurfural. 
Other examples of applications of enzymatic co-immobilization by gel encapsulation are given by studies of Long and co-workers [81,82] on the production of lactosucrose. Sankar et al. [71] co-immobilized laccase, cellulose, and $\beta$-glucosidase for the pretreatment of lignocellulosic biomass.

\subsubsection{Metal-Organic Framework (MOF) Encapsulation}

Metal-organic frameworks (MOFs) have recently garnered consideration as an attractive solid substrate because the highly tunable MOF framework can not only serve as an inert host but also enhance the selectivity, stability, and/or activity of the enzymes. Wu et al. [165] created a new biocatalyst using a coprecipitation process of glucose oxidase (GOx) and horseradish peroxidase (HRP) in an aqueous solution containing zinc ions and 2-methylimidazole, under ambient conditions. The product formed (GOx and HRP/ZIF-8), in which the enzymes were co-immobilized in ZIF-8, a zeolite imidazolate MOF based on zinc and 2-methylimidazole, was tested for its ability to detect glucose using 2,2'-azino-bis (3-ethylbenzothiazoline-6-sulphonic acid) (ABTS) as chromogenic substrate. For this to happen, GOx must convert glucose to gluconic acid, while the $\mathrm{H}_{2} \mathrm{O}_{2}$ generated serves as a substrate for HRP to oxidize $\mathrm{ABTS}^{2-}$ to $\mathrm{ABTS}^{-}$, whose absorbance is measured at $415 \mathrm{~nm}$. As a result, good linearity was obtained for concentrations between $0-100 \mu \mathrm{M}$ of glucose. As for its stability, after 7 days of storage in $\mathrm{pH} 7.4$ phosphate buffer saline solution at room temperature, the biocatalyst retained about $80 \%$ of its initial enzymatic activity, while free enzymes lose $50 \%$ of their activity within 2 days.

In his work using GOx and HRP, Chen and co-workers [83] created the catalyst NMOF@ GOx/HPR, in which both enzymes are co-immobilized in a nanocrystaline ZIF$8 \mathrm{MOF}$. The reaction, which consists of using $\mathrm{H}_{2} \mathrm{O}_{2}$ to oxidize the compound Amplex Red to Resofurin, catalyzed by HPR, was 7.5 times higher using the new biocatalyst in comparison with the reaction in a homogeneous medium. When compared to the coencapsulation of the same enzymes in $\mathrm{SiO}_{2}$ and acrylamide hydrogel, these biocatalysts increased only 2 and 2.5 times in comparison with the homogeneous medium, respectively. Immobilization of $\beta$-galactosidase $(\beta$-Gal) was also tested in conjunction with GOx and HRP, resulting in the catalyst NMOF @ $\beta-G a l / G O x / H R P$. The lactose hydrolysis cascade by $\beta$-Gal, which generates galactose and glucose, which is a substrate for GOx, was 5.3 times greater for the new biocatalyst, compared to the reaction in a homogeneous medium. In the same work, they also tested the ability to use NMOFs to operate cascades with enzymes that require cofactors. To do this, they first covalently linked $\mathrm{NAD}^{+}$to the phenylboronic acid conjugated poly (allylamine) polymer, followed by encapsulation in NMOF with alcohol dehydrogenase $(\mathrm{AlcDH})$. AlcDH reduces the polymer-NAD ${ }^{+}$to polymer-NADH, by ethanol, which in turn reduces methylene blue $\left(\mathrm{MB}^{+}\right)$to $\mathrm{MBH}$. This encapsulation resulted in a 5 times greater reduction when compared to the reaction in a homogeneous system. Afterward, the AlcDH/NAD ${ }^{+}$-polymer system was coupled to the enzyme $\mathrm{NAD}^{+}$-dependent lactate dehydrogenase (LacDH) and encapsulated in ZIF-8. In the presence of $\mathrm{LacDH}$, the polymer-NADH, which was generated by the reduction of polymer-NAD ${ }^{+}$by AlcDH to oxidize ethanol to acetaldehyde, reduces pyruvic acid to lactic acid. There was a 4.7-fold increase in pyruvic acid to lactic acid when compared to the free system. Furthermore, the GOx/HRP and AlcDH/NAD ${ }^{+}$-polymer/LacDH cascades did not significantly decrease after three weeks of storage at room temperature. Other GOx and HRP co-encapsulation methodologies for glucose detection have been described [166,167].

The combination of enzyme co-immobilization and membrane co-enzymes by MOF was used by Zhu and co-workers [84] for the reduction of $\mathrm{CO}_{2}$ to methanol (Figure 5a). Additionally, using precipitation formation biocatalyst methodology, the pairs of enzymes formate dehydrogenase (FDH) and L-Glutamic dehydrogenase (GDH), formaldehyde dehydrogenase (FalDH) and GDH, alcohol dehydrogenase (ADH) and GDH were encapsulated with or without nicotinamide adenine dinucleotide (NADH). The products enzymes/ZIF8 and Enzymes and Co-enzymes/ZIF-8 (Figure 5b) were tested directly in an aqueous medium, containing $\mathrm{NADH}$, L-glutamate and saturated with $\mathrm{CO}_{2}$, and immobilized in a 
pervaporation cell equipped with a PVDF membrane, which can separate methanol and water (Figure 5c). The highest concentration of methanol, $15 \mathrm{mM}$, was obtained for the Enzymes and Co-enzymes/ZIF-8 biocatalysts immobilized on the membrane in the sequential order of reactions (OECMM), for $4 \mathrm{~h}$ of operation and total flux of $25.3 \mathrm{~g} \cdot \mathrm{m}^{-2} \cdot \mathrm{h}^{-1}$. This is due to the greater proximity of NADH with the enzymes, since it is available within the MOF, in addition to biocatalyst positioning in the membrane, which allows a better transfer of intermediates, and separation of the product through the PVDF membrane. The highest amount of methanol, around $18 \mu \mathrm{mol}$, was verified at $12 \mathrm{~h}$ of the experiment, in the OECMM reaction, but its production rate decreases, once the enzymes lose their activity.

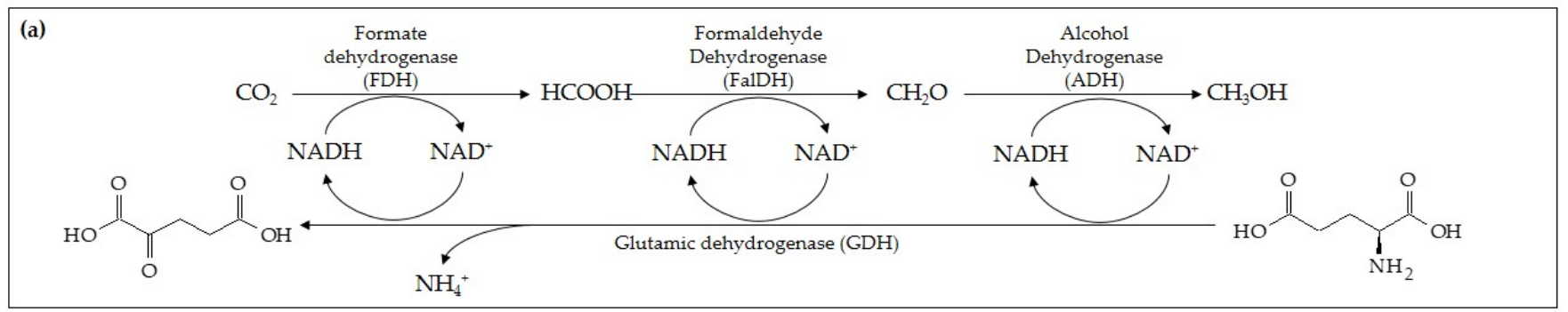

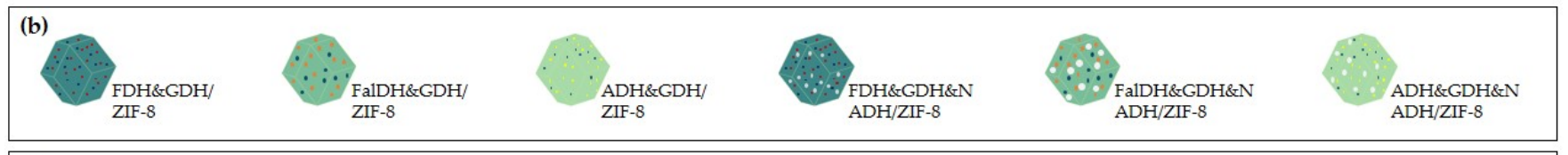

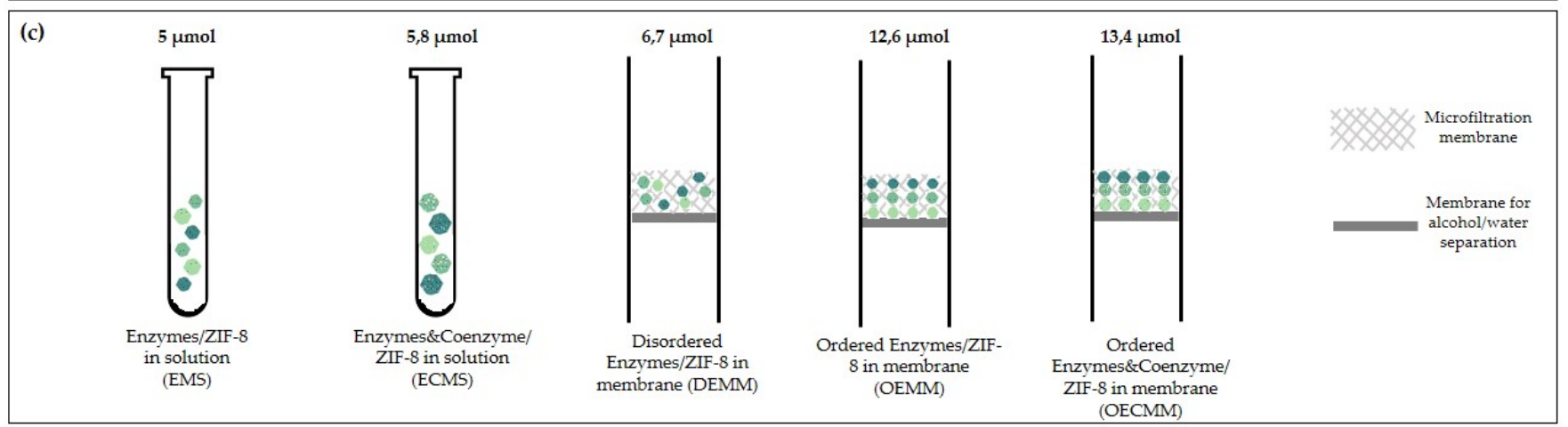

Figure 5. (a) Reactions involved in converting $\mathrm{CO}_{2}$ to methanol and NADH regeneration, (b) biocatalysts developed by Zhu and co-workers [84] and (c) amount of methanol produced by immobilized enzymes (total flux is $25.30 \mathrm{~g} \cdot \mathrm{m}^{-2} \cdot \mathrm{h}^{-1}$ and operation time is $6 \mathrm{~h}$ ).

Another application using NADH regeneration by GDH was proposed by Ren et al. [85], for the conversion of $\mathrm{CO}_{2}$ to formate. For this, the Co-IMR and Mix-IMR biocatalysts were created. The first contains carbonic anhydrase (CA), FDH, NADH, GDH, and PEI mixed in zinc nitrate solution and precipitated in 2-methylimidazole solution; the second consists of ZIF-8 containing CA and Fate DH, and another ZIF-8 with NADH, GDH, and PEI. For the experiments, these catalysts and free enzymes were tested in a PBS solution containing $\mathrm{CO}_{2}$ and L-glutamate. When the Co-IMR biocatalyst without PEI was tested, there was no production of format, which may indicate that there was a loss of NADH, since it is not tied to ZIF-8 by PEI. The same result was obtained for Co-IMR without GDH. The highest yield was found in the system with free enzymes. However, the Co-IMR biocatalyst can be used for up to 8 cycles with a productivity loss of $50 \%$. At the end of the eighth cycle, its accumulated yield was 4.5 times the yield when using free enzymes.

\subsubsection{Nanofibers Encapsulation}

The use of hollow nanofibers with encapsulated enzymes to reduce $\mathrm{CO} 2$ to methanol has been reported [86]. On the inner surface of the nanofiber, Fate DH, ADH and GDH are encapsulated together with NADH and poly (allylamine hydrochloride) (PAH), which 
acts as an anchorage for enzymes and the cofactor. On the outer surface of the nanofiber, $\mathrm{CA}$ is immobilized. After encapsulation, all enzymes retained more than $60 \%$ compared to their activity when in the free system. For free enzymes, the NADH-based methanol yield of the homogeneous system was $36 \%$, while the immobilized system achieved a yield of $103 \%$, with a maximum concentration of $68.8 \mu \mathrm{M}$ of methanol. After 10 cycles of reuse, the catalyst retained more than $80 \%$ of its original activity, with a cumulative methanol yield of $940 \%$.

\subsubsection{Polymersomes}

Klermund and co-workers [87], used the encapsulation technique in polymersomes for the synthesis of CMP- $\mathrm{N}$-acetylneuraminic acid (CMP-Neu5Ac) from $\mathrm{N}$-acetylglucosamine (GlcNAc), pyruvate, and cytidine triphosphate (CTP). For this, the allosteric enzyme $\mathrm{N}$-acylD-glucosamine 2-epimerase (AGE) and its cofactor adenosine triphosphate (ATP) convert GlcNAc to $N$-acetylmannosamine (ManNAc), which into a condensation aldol catalyzed by $\mathrm{N}$-acetylneuraminate lyase (NAL), reacts with pyruvate and forms $\mathrm{N}$-acetylneuraminic acid (Neu5Ac). This, by the action of CMP-sialic acid synthetase (CSS), is activated with cytidine triphosphate (CTP) and converted to (CMP-Neu5Ac). Since AGE is inhibited by CTP, this enzyme, together with ATP, was encapsulated within the lumen of the polymersome. The enzymes NAL and CSS were immobilized on the outer surface, using hydrophobic peptide anchors. To enable the mass transfer of GlcNAC and ManNAc into and out of the polymersome, respectively, the channel protein OmpF G119D was incorporated into the membrane. With that, a concentration of $0.87 \mathrm{mM}$ of CMP-Neu5Ac was obtained, with $93 \mathrm{~h}$ of reaction. For a system with free enzymes, no product formation was verified.

\section{Co-Immobilization of Enzymes and Non-Enzymatic Catalysts}

Co-immobilization of enzymes and non-enzymatic catalysts on insoluble matrices has recently emerged as a useful strategy in the development of one-pot/one-step chemoenzymatic cascades. The resulting single hybrid catalysts have been termed multicatalytic materials (MCMs) or multicatalytic hybrid materials (MCHM) [168] or chemo-bio nanoreactors (CBNs) [20]. In comparison to the conventional use of two separated catalysts, combining them in the same material may confer advantages such as operationally simpler procedures for cascade reactions, easier recovery of both catalysts, and synergism between the catalytic steps. In addition, compartmentalization can be provided by designing multicatalytic materials in which different catalysts occupy distinct "active sites", thus being an approach for circumventing incompatibility between catalysts, particularly chemocatalysts and enzymes. Some matrices that have been used for co-immobilization of enzymes and chemocatalysts are summarized in Table 3.

Table 3. Matrices used in the co-immobilization of chemo- and biocatalysts. CAL-B $=$ Candida antarctica $\mathrm{B}$ lipase, $\mathrm{DKR}=\mathrm{dy}-$ namic kinetic resolution, $\mathrm{KR}=$ kinetic resolution, $\mathrm{ADH}=$ alcohol dehydrogenase, $\mathrm{PDA}=$ polydopamine, $\mathrm{CAL}-\mathrm{A}=\mathrm{Candida}$ antarctica A lipase, $\mathrm{MOF}=$ metal-organic framework, $\mathrm{LAAO}=\mathrm{L}$-amino acid oxidase $\mathrm{NaDC}=$ sodium deoxycholate, Mi-methyl-imidazol, MBN = metal-biosurfactant nanocomposite.

\begin{tabular}{|c|c|c|}
\hline Matrix & Biocatalyst/Chemocatalyst & Applications \\
\hline \multirow{2}{*}{ Siliceous mesocellular foam } & CAL-B/Pd & $\begin{array}{c}\text { DKR of amines [169]; ketone reduction/KR } \\
\text { cascade }[170,171]\end{array}$ \\
\hline & Laccase/Pd & $\begin{array}{l}\text { Oxidation of alcohols [172] and 2-substituted- } \\
\text { 2,3-dihydroquinazolin-4(1H)-ones [173] }\end{array}$ \\
\hline Silica nanoparticles & CAL-B/Pd & $\begin{array}{l}\text { DKR of amines [174,175]; aldehyde } \\
\text { reduction/alcohol esterification cascade [176] }\end{array}$ \\
\hline Silica-coated iron oxide nanoparticles & $\mathrm{CAL}-\mathrm{B} / \mathrm{Pd}$ & DKR of amines [177] \\
\hline \multirow[b]{2}{*}{ Dendritic organosilica nanoparticles } & $\mathrm{CAL}-\mathrm{B} / \mathrm{Pd}$ & DKR of amines [178] \\
\hline & $\mathrm{Pd} / \mathrm{ADH}$ & $\begin{array}{l}\mathrm{Pd} / \mathrm{Cu} \text {-catalyzed Liebeskind-Strogl } \\
\text { reaction/bioreduction cascade [178] }\end{array}$ \\
\hline
\end{tabular}


Table 3. Cont.

\begin{tabular}{|c|c|c|}
\hline Matrix & Biocatalyst/Chemocatalyst & Applications \\
\hline PDA nanostructures & $\mathrm{Pd}, \mathrm{Pt} / \mathrm{CAL}-\mathrm{B} ; \mathrm{Pd}, \mathrm{Pt} / \mathrm{CAL}-\mathrm{A}$ & DKR of amines [179] \\
\hline \multirow{2}{*}{ UiO-66 (MOF) } & Pd/CAL-B & $\begin{array}{c}\text { aldehyde reduction/alcohol esterification } \\
\text { cascade [180] }\end{array}$ \\
\hline & $\mathrm{Pt} / \mathrm{LAAO}$ & Oxidative deamination of L-tryptophan [181] \\
\hline ZIF-67 (MOF) & Pd/CAL-A & $\begin{array}{l}\text { Nitroaldol reaction/DKR of alcohols } \\
\text { cascade [182] }\end{array}$ \\
\hline HKUST-1 (MOF) & $\mathrm{Cu} / \mathrm{ADH}$ & Benzaldehyde oxidation [183] \\
\hline $\mathrm{NaDC} / \mathrm{Mi} \mathrm{MBN}$ & Shvö's catalyst/CAL-B & DKR of alcohols and amines [184] \\
\hline Carbon nitride $\left(\mathrm{C}_{3} \mathrm{~N}_{4}\right)$ & $\mathrm{Pd} / \mathrm{CAL}-\mathrm{B}$ & $\begin{array}{c}\text { aldehyde reduction/alcohol esterification } \\
\text { cascade [185] }\end{array}$ \\
\hline
\end{tabular}

There are fewer reports of co-immobilization of enzymes and chemocatalysts to date when compared to co-immobilization of enzymes solely. Although most enzymes are compatible with each other and operate under similar conditions, mutual inactivation and different, divergent operational conditions are often a crucial issue in the development of chemo-bio hybrid catalysts. On the other hand, co-immobilization per se can tackle this challenge by improving (bio)catalyst stability and providing compartmentalization in some cases. Most examples of chemo-bio hybrid catalysts rely on the co-immobilization of lipases and transition metals, especially CAL-B and Pd. Pioneered by Reetz and Schimossek in the $90 \mathrm{~s}$ [186], the combination of Pd and immobilized lipases in a conventional "two catalysts" one-pot-one-step cascade has been shown feasible, being a well-established method for dynamic kinetic resolution of amines, in which enzymatic kinetic resolution and Pd-mediated amine racemization take place concurrently. Because some lipases are thermostable and tolerant to organic solvents, they are a convenient choice for the development of hybrid catalysts to be employed in one-pot/one-step cascades.

\subsection{Co-Immobilization of Enzymes and Metals in Siliceous Materials}

The concept of co-immobilizing enzymes and metals into porous matrices to provide a single heterogeneous hybrid catalyst was first reported by Bäckvall's group [169]. For this purpose, Pd nanoparticles were immobilized in a siliceous mesocellular foam (MCF) functionalized with aminopropyl groups to furnish a $\mathrm{Pd}^{0}-\mathrm{AmP}-\mathrm{MCF}$, which had been previously reported by Bäckvall's group as a heterogeneous catalyst for the racemization of amines [187]. Taking advantage of amino groups in the porous of the support, lipase $\mathrm{B}$ of Candida antarctica (CAL-B) was then immobilized into Pd0-AmP-MCF by covalent link through the addition of glutaraldehyde (Figure 6). A stepwise co-immobilization procedure in which metal immobilization takes place first was required since the harsh conditions needed to generate $\mathrm{Pd}$ nanoparticles would lead to enzyme inactivation. The procedure for lipase immobilization, in turn, did not cause significant metal clustering, so that well-dispersed Pd nanoparticles with 1-2 nm size range in the as-prepared hybris catalyst were observed by TEM and STEM analysis. Enzymes and Pd nanoparticles were immobilized in the same cavities with loadings of $15.5 \mathrm{wt} . \%$ and $4.80 \mathrm{wt} . \%$, respectively. Reducing lipase loading did not result in an improvement of $\mathrm{Pd}$-mediated racemization rate, thus suggesting that although being in the same pore, enzyme and metal were separated enough to prevent mutual deactivating. The hybrid catalyst was assayed in the DKR of 1-phenylethylamine to furnish the product with $95 \%$ yield and 99\% ee (enantiomeric excess) in $16 \mathrm{~h}$ (Scheme 1). For comparison, $89 \%$ yield and $99 \%$ ee were achieved by performing the reaction with separated immobilized Pd and lipase in MCF at the same loadings. The higher efficiency of the hybrid catalyst was ascribed to the proximity of Pd and CAL-B, which could allow a more efficient cooperative catalysis with KR and racemization steps occurring in the same cavity. The hybrid catalyst, however, could not be used for more 
than two cycles to obtain the product with good yields in reasonable reaction times. The poor recyclability was ascribed to enzyme denaturation and suggested to be related to the polar character of the support. Nevertheless, this was the first report of a DKR performed by a single heterogeneous catalyst.

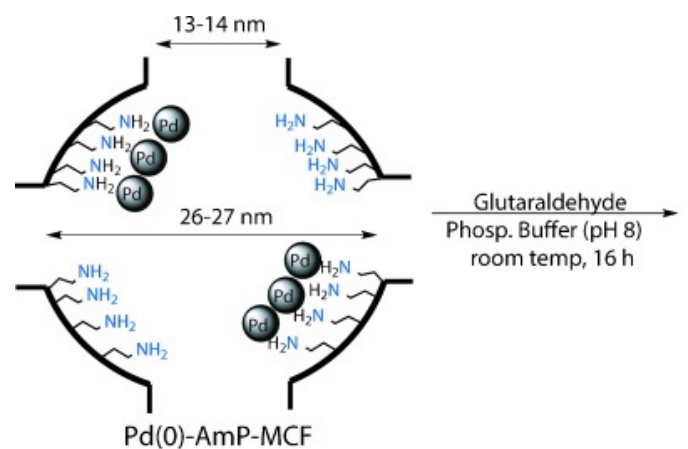

Figure 6. Co-immobilization of
license of John Wiley and Sons.<smiles>CC(N)c1ccccc1</smiles><smiles>CCOC(=O)COC</smiles>

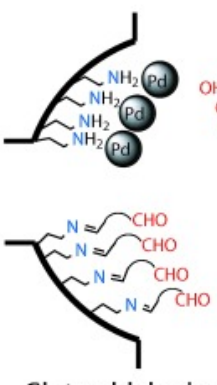

Glutaraldehyde-functionalized $\mathrm{Pd}(0)-\mathrm{AmP}-\mathrm{MCF}$

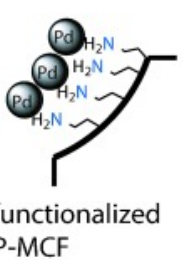

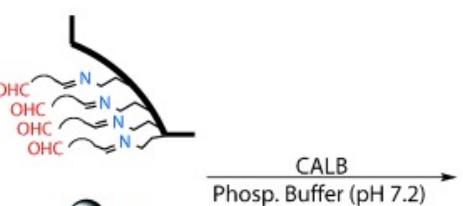
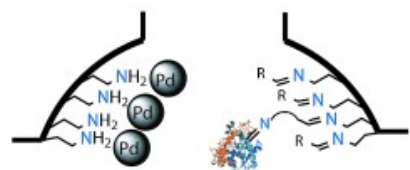

room temp, $16 \mathrm{~h}$
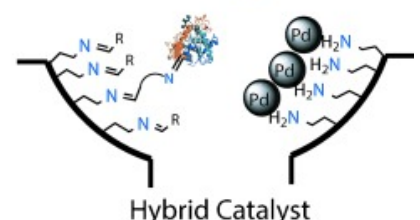

Hybrid Catalyst

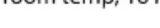

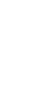

Pd and CAL-B into pores of siliceous mesocellular foam [169]. Reprinted from [169] with<smiles>CCOC(=O)CC</smiles>

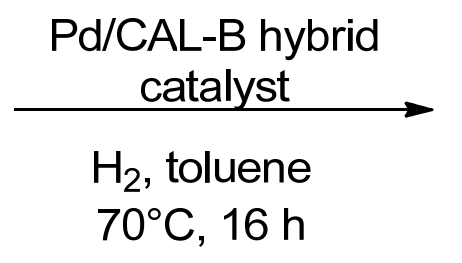<smiles>COCC(=O)N[C@@H](C)c1ccccc1</smiles>

95\% yield, $99 \%$ ee

Scheme 1. Dynamic kinetic resolution of 1-phenylethylamine performed with a Pd/CAL-B hybrid catalyst [169].

The co-immobilization of Pd and lipase in cavities of MCF as described by Bäckvall [169] has also been reported by Magadum and Yadav [170,171]. For instance, a CAL$\mathrm{B} / \mathrm{Pd}$ hybrid catalyst was employed in a one-pot two steps reduction/kinetic resolution cascade to give enantiopure (R)-phenyl ethyl acetate from acetophenone (Scheme 2) [170].<smiles>CC(=O)c1ccccc1</smiles>

\section{Pd/CAL-B hybrid catalyst}

$\mathrm{H}_{2}$, n-hexane $50^{\circ} \mathrm{C}, 10 \mathrm{~h}$<smiles>C[C@H](O)c1ccccc1</smiles>

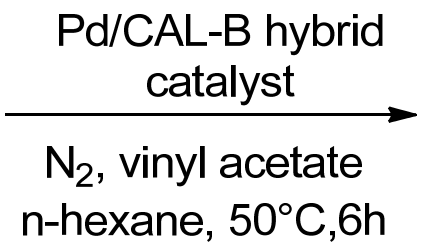<smiles>CC(=O)O[C@@H](C)c1ccccc1</smiles>

\section{$49.11 \%$ yield $>99 \%$ ee}

Scheme 2. One-pot reduction/kinetic resolution cascade catalyzed by a Pd/CAL-B hybrid catalyst [173].

The method for co-immobilization of metal and enzyme into MCF introduced by Bäckvall [170] has also proven useful to produce a laccase/Pd hybrid catalyst [172]. Laccases are copper enzymes that can oxidize compounds under mild conditions employing molecular oxygen as an oxidizing agent to give water as a byproduct. Combination of laccase and Pd in a single heterogeneous catalyst allowed for oxidation of alcohols in aqueous media and room temperature to give aldehydes in good to excellent isolated yields (Scheme 3) [172]. In this reaction, laccase acts as an oxygen-activating catalyst while 
Pd serves as an oxidizing catalyst. Molecular oxygen could be used as the terminal oxidant while hydroquinone was required as an electron transfer mediator in catalytic amounts. It is worth noting that control experiments using each catalytic component at a time showed that the triple action of the hybrid catalyst, hydroquinone, and air are required for the reaction to occur to a reasonable extent. The reaction could be performed both under oxygen atmosphere (oxygen balloon) and in an open-air flask, though the latter provided minor yields, and the catalyst could be reused at least seven times without a drop in yield. In addition, the catalyst was also found to oxidize secondary alcohols to ketones, to convert cyclohexanol into phenol, and to promote aerobic oxidative aromatization of N-heterocyclic compounds, thus being able to oxidize $\mathrm{C}-\mathrm{O}, \mathrm{C}-\mathrm{C}$, and $\mathrm{C}-\mathrm{N}$ bonds. The ease of recovery and recyclability of laccase/Pd hybrid catalyst could be further improved by co-immobilizing Pd nanoparticles and enzymes into magnetic MCF [173].<smiles>[R]C([1H])O</smiles>

$\mathrm{R}=$ aryl, heteroaryl, alkyl

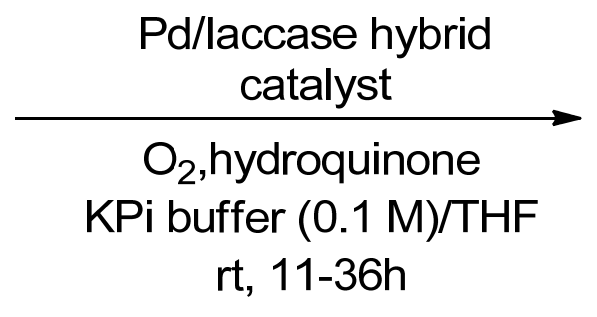<smiles>[R]C=O</smiles>

\section{$75-85 \%$ isolated yield 10 examples}

Scheme 3. Oxidation of alcohols in aqueous media catalyzed by a Pd/laccase hybrid catalyst [175].

Co-immobilization of Pd and lipase on the surface of silica nanoparticles have been reported to provide heterogeneous hybrid catalysts for dynamic kinetic resolution of amines. The multicatalytic materials are prepared by adsorption of Pd nanoparticles by reduction of $\mathrm{Pd}(\mathrm{II})$ in the presence of silica nanoparticles, which are then functionalized with amino groups to allow covalent attachment of lipase through glutaraldehyde or epichlorohydrin method [174]. A similar method has been reported for the co-immobilization of Pd and lipase on the surface of silica-coated iron oxide nanoparticles to produce a magnetic hybrid catalyst [177]. The usefulness of this easily recoverable heterogeneous hybrid catalyst was showed in the DKR of 1-phenylethylamine in both batch and continuous flow conditions resulting in high conversions and enantioselectivity.

Dendritic organosilica nanoparticles (DONs) are hydrophobic materials with ordered center-radial mesoporous channels presenting internal surface areas that can be easily accessed. The use of DONs to co-immobilize Pd and lipase CAL-B has been recently reported [178]. In this work, Pd was immobilized in DONs through in situ reduction, which was followed by immobilization of lipase through physical adsorption. The asprepared nanocatalyst containing metal nanoparticles and enzymes was coated with a hydrophilic polydopamine shell through self-polymerization of dopamine on DONs interface to give a core-shell nanocatalyst in which the catalytic sites are in the hydrophobic core and protected by a hydrophilic shell, which could also allow for better dispersion in water. Both PDA-shell-protected and non-protected nanocatalysts were used for DKR of 1-phenylethylamine in toluene at $60{ }^{\circ} \mathrm{C}$. The latter was found to be more efficient and lead to a higher yield than the former, which, conversely, showed better recyclability, which was ascribed to the protective PDA shell. The versatility and potential of the concept were demonstrated by the co-immobilization of an alcohol dehydrogenase (ADH) from Rhodococcus rubber and Pd in DON to give a PDA-coated hybrid catalyst to promote a two-step one-pot cascade reaction involving a $\mathrm{Pd} / \mathrm{Cu}$-catalyzed Liebeskind-Strogl reaction to obtain phenyl methyl ketones and an asymmetric bioreduction for the synthesis of enantiopure alcohols (Scheme 4). A major challenge in this cascade relies on the mutual inactivation of ADH and copper ions, which could be circumvented using a core-shell PD/ADH hybrid catalyst, since the protective PDA shell was found to prevent copper ions to enter the internal microenvironment, thus preserving the enzyme. In addition, the 
$\mathrm{Pd} / \mathrm{ADH}$ core-shell hybrid nanocatalyst could provide the product with a yield higher than $60 \%$ and ee higher than $95 \%$ when used for the fourth run without any detectable leaching of metal and enzyme. Better dispersibility in water due to the PDA shell, improved absorption of organic reactants due to hydrophobic nature of the core, and decrease in the diffusion distance between reaction intermediates due to proximity of catalysts were suggested to important advantages of this type of hybrid catalyst.<smiles>[R]c1ccc(Br)cc1</smiles>

$\mathrm{R}=\mathrm{H}$, halogen, $-\mathrm{CH}_{3},-\mathrm{CF}_{3}$<smiles>CC(=O)SC(C)(C)C</smiles>

\section{Tris-HCl buffer (pH 8.0) n-heptane, $i-\mathrm{PrOH}, 24 \mathrm{~h}, 37^{\circ} \mathrm{C}$}<smiles>[R]c1ccc([C@@H](C)O)cc1</smiles>

\section{$61-86 \%$ yield $97-99 \%$ ee 6 examples}

Scheme 4. Liebeskind-Strogl reaction/bioreduction cascade catalyzed by a Pd/ADH hybrid catalyst [178].

The above-mentioned strategies have been found to be useful in the development of heterogeneous metal-enzyme hybrid catalysts with improved performance and ease of recovered, though its scope beyond Pd and lipases and laccases is still to be exploited. In this sense, compartmentalization of chemo- and bioactive species within a single nanocatalyst might be advantageous or even crucial to overcome incompatibility issues and to expand the repertoire of hybrid chemobiocatalysts. For this purpose, Zhang and co-workers [175] designed a core-shell type nanoreactor in which metal and enzyme are immobilized in separated domains. The hybrid catalyst was prepared by immobilizing Pd through in situ reduction of $\mathrm{Pd}(\mathrm{II})$ on mesoporous silica nanosphere modified with amino groups $\left(\mathrm{NH}_{2}-\mathrm{MSN}\right)$ to give the core material $\mathrm{Pd} / \mathrm{NH}_{2}-\mathrm{MSN}$, which was then protected with a sacrificial silica layer through treatment with TEOS and 1,2-bis(trimethoxysily)ethane (BTME) to provide yolk-shell nanospheres (Pd/ $\left.\mathrm{NH}_{2}-\mathrm{MSN} @ \mathrm{BTME}\right)$. The yolk-shell nanospheres were further coated with a mesoporous silica through a biphasic stratification approach that allowed for a mesoporous silica shell presenting a dendritic pore structure presenting large pores (Figure 7). CAL-B enzyme immobilization on the so-prepared yolk-shell@shell nanospheres was performed through adsorption, resulting in high enzyme loading due to adsorption in mesochannels instead of on the outer surface. Nitrogen sorption isotherm studies revealed mesopores with mean size of $2.3 \mathrm{~nm}$ in the inner core and pores with mean size of $7.2 \mathrm{~nm}$ in the outer shell. Such hierarchical structures were suggested not only to allow high enzyme loading on the outer shell but also to prevent diffusion of enzymes to the inner core, thus ensuring proper separation of metal and enzyme sites. This hybrid catalyst has been found to catalyze DKR of 1-phenylethylamine with excellent enantioselectivity and high conversions (98\%) after $8 \mathrm{~h}$ at $70{ }^{\circ} \mathrm{C}$ but moderate yield (63\%) due to decreased selectivity resulting from side reactions in the racemization step. DRK of 1-phenylethylamine was also carried out with a mixture of monofunctional Pd and lipase catalysts immobilized in the same fashion as the hybrid yolk-shell@shell catalyst and was showed to require longer reaction times $(12 \mathrm{~h})$ to achieve lower conversion $(69 \%)$ and somewhat lower yield (55\%). The higher efficiency of the hybrid catalyst was ascribed not only to catalyst compartmentalization but also to the diffusion pathway provided for the reactants along the nanospheres. The hybrid catalyst could be reused at least three times but not without a loss in efficiency and a decrease in yield from $63 \%$ to $41 \%$, although morphological parameters of the catalyst were retained. 


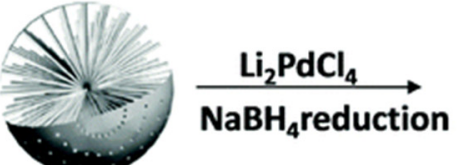

$\mathrm{NH}_{2}-\mathrm{MSN}$

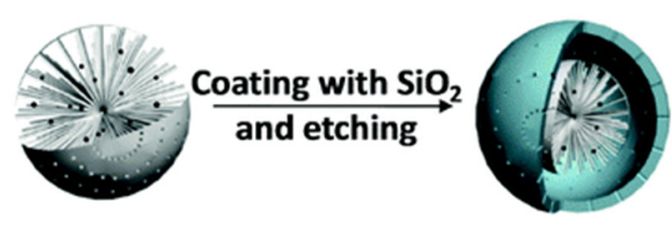

$\mathrm{Pd} / \mathrm{NH}_{2}-\mathrm{MSN}$
$\mathrm{Pd} / \mathrm{NH}_{2}-\mathrm{MSN} @ B T M E$

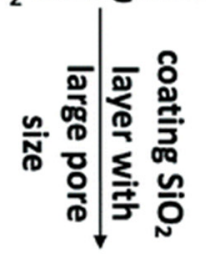

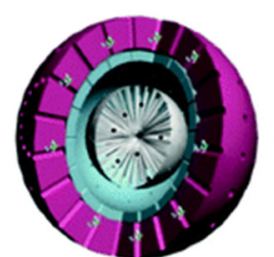

$\mathrm{Pd} / \mathrm{NH}_{2}-\mathrm{MSN} @ B T M E$ @enzyme/L-mesosilica
Pd/NH2-MSN@BTME@L-mesosilica

Figure 7. Preparation of a Pd/CAL-B yolk@shell-shell catalyst [175]. Reprinted from [175] with permission of Royal Society of Chemistry.

A similar core-shell approach to produce nanocatalysts in which metal and enzyme are spatially separated has been reported by Gao and co-workers [179]. In this work, a bimetallic Pd-Pt core coated with polydopamine (PDA) was prepared in a single step through treatment of metal precursors with the surfactant Pluronic F127 and dopamine in aqueous solutions. Oxidative polymerization of dopamine led to the reduction of metal ions so that no additional reducing agent was required, whereas Pluronic F127 was found to play an important role in preventing particles agglomeration and producing mesopores. The resulting polydopamine bimetallic core-shell structure (Pd-Pt@PDA) presented mesopores sizes of about $3 \mathrm{~nm}$ in the core and $8 \mathrm{~nm}$ in the shell. Enzymes were then covalently immobilized on the PDA shell to give hybrid Pd-Pt@PDA@enzyme nanocatalysts (Figure 8). The versatility of this method was demonstrated for the co-immobilization of $\mathrm{Pd}$ and $\mathrm{Pt}$ with lipases CAL-B and CAL-A, and organophosphorus hydrolase (OPH), the metal-lipase hybrids being used in DKR of amines and the latter in a hydrolysis/nitro reduction cascade assay for conversion of parathion-methyl to 4-aminophenol. DKR of amines with PdPt@PDA@CAL-B could be performed with high yields (85-99\%) and enantioselectivity (94-98\% ee) for six different benzylic amines. Recycling studies showed no evidence of metal or enzyme leaching after five cycles but a decrease in enzyme activity, which was suggested to account for a decrease in yield and increase in byproducts.

Another approach for producing hybrid catalyst with metal and enzymes in separate locations relies on loading metal nanoparticles inside the pores of mesoporous silica nanoparticles and immobilizing enzymes on the surface through hydrophobic interactions. This approach was employed by Zhang and co-workers [176] to co-immobilize Pd and CAL-B. Importantly, they have shown that the hydrophobicity of the hybrid catalyst could be tailored by postmodification of Pd-loaded silica nanoparticles surface with alkyl chains through reaction with trimethoxy(octadecyl)silane before enzyme immobilization step. The enhanced hydrophobicity of the surface of nanoparticles allowed for higher enzyme loading, easier diffusion of nonpolar substrates across the nanostructure, and better dispersion in organic solvents. The hydrophobic surface was also suggested to be beneficial for CAL-B, which is an enzyme that displays interfacial activation. The hybrid catalyst was showed to be efficient in a one-pot reduction/transesterification cascade to synthesize benzyl hexanoate from benzaldehyde and ethyl hexanoate. Comparative studies 
suggested a cooperative effect of Pd and CAL-B in the hybrid catalyst since lower yields were obtained by performing the cascade reaction with Pd and CAL-B as distinct catalysts. In addition, only $0.11 \%$ Pd leaching, and no morphological changes were observed in the $\mathrm{Pd} / \mathrm{CAL}-\mathrm{B}$ hybrid catalyst after four times of reuse, whereas cascade reaction yield could be catalyzed to give a yield of $80 \%$ of that obtained in the first run.
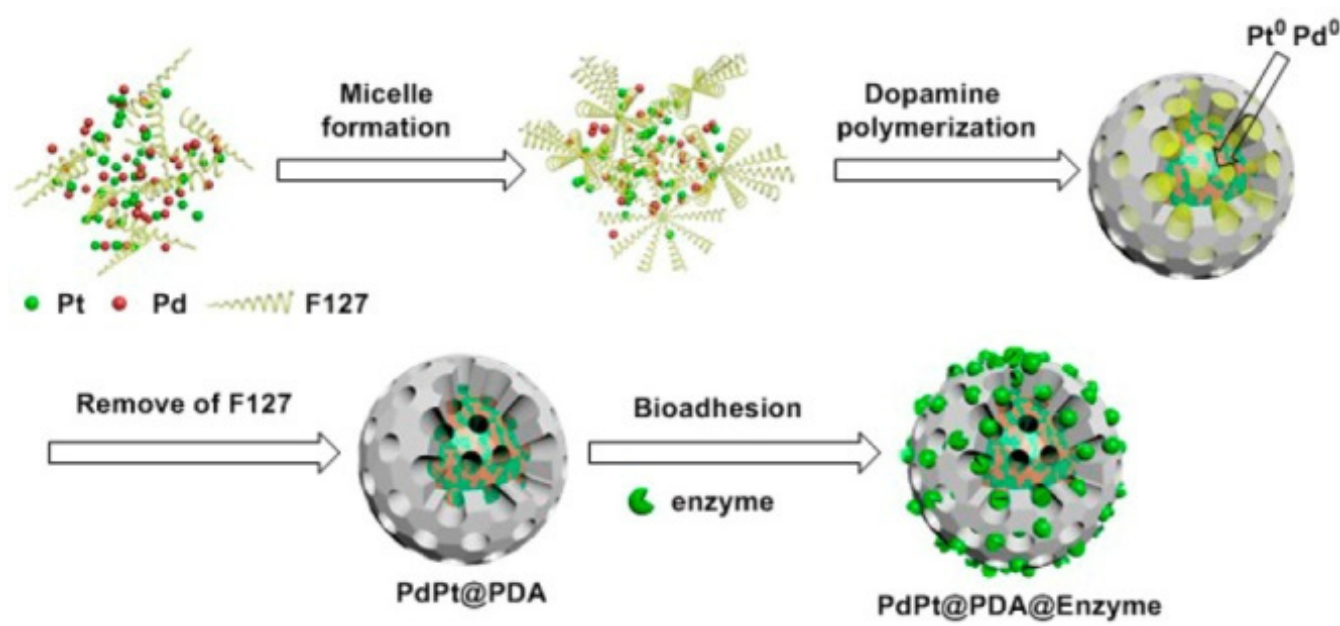

Figure 8. Preparation of a Pd-Pt/lipase core-shell catalyst [179]. Reprinted with permission from [179]. Copyright (2020) American Chemical Society.

\subsection{Co-Immobilization of Enzymes and Metals in Non-Siliceous Materials}

Metal-organic frameworks (MOFs) have been emerging as useful matrices for enzyme immobilization. Among advantages of MOFs are their high surface areas, high porosity, adjustable pores with dimensions compatible with enzyme sizes, and diversity of synthetic methods and architectures Importantly, these matrices present tunability, their properties being tuned by the choice of metal and organic linker or through post-synthetic methods.

Although reports of immobilization of one or more enzymes in MOFs are more abundant, some examples of co-immobilization of bio- and chemocatalysts for the more challenging chemoenzymatic cascades have been recently reported. For instance, a Pd/CAL-B hybrid catalyst could be obtained using $\mathrm{UiO}-66-\mathrm{NH}_{2}$, which is a MOF composed of $\mathrm{Zr}$-oxo clusters and 2-aminotherephthalic acid [180]. Metal and enzymes were in separate sites, which was achieved by preparing MOFs with pore sizes smaller than $5 \mathrm{~nm}$ so that Pd nanoparticles were immobilized through in situ reduction within the pores while lipases were physically adsorbed on the surface, thus leading to compartmentalization (Figure 9). In addition, the use of benzoic acid during the preparation of the MOF allowed for further tuning of hydrophobicity through the exchange of benzoic acid with lauric acid. A proper hydrophobicity may not only improve protein adsorption but also account for a better dispersion of the hybrid catalysts in organic solvents, which is especially advantageous for chemoenzymatic cascades involving hydrophobic reactants and intermediates or reaction that cannot be performed in water. The usefulness of the Pd/CAL-B hybrid catalyst based on UiO-66- $\mathrm{NH}_{2}$ was showed in a metal-mediated reduction/lipase-catalyzed esterification cascade reaction in toluene to obtain benzyl hexanoate from benzaldehyde and ethyl hexanoate leading to $100 \%$ yield in $8 \mathrm{~h}$. The hybrid catalyst could be reused at least three times with a loss of $20 \%$ in yield and leaching of $\mathrm{Pd}$ of $1.08 \%$, whereas no leaching but denaturation of the enzyme was suggested to occur. 


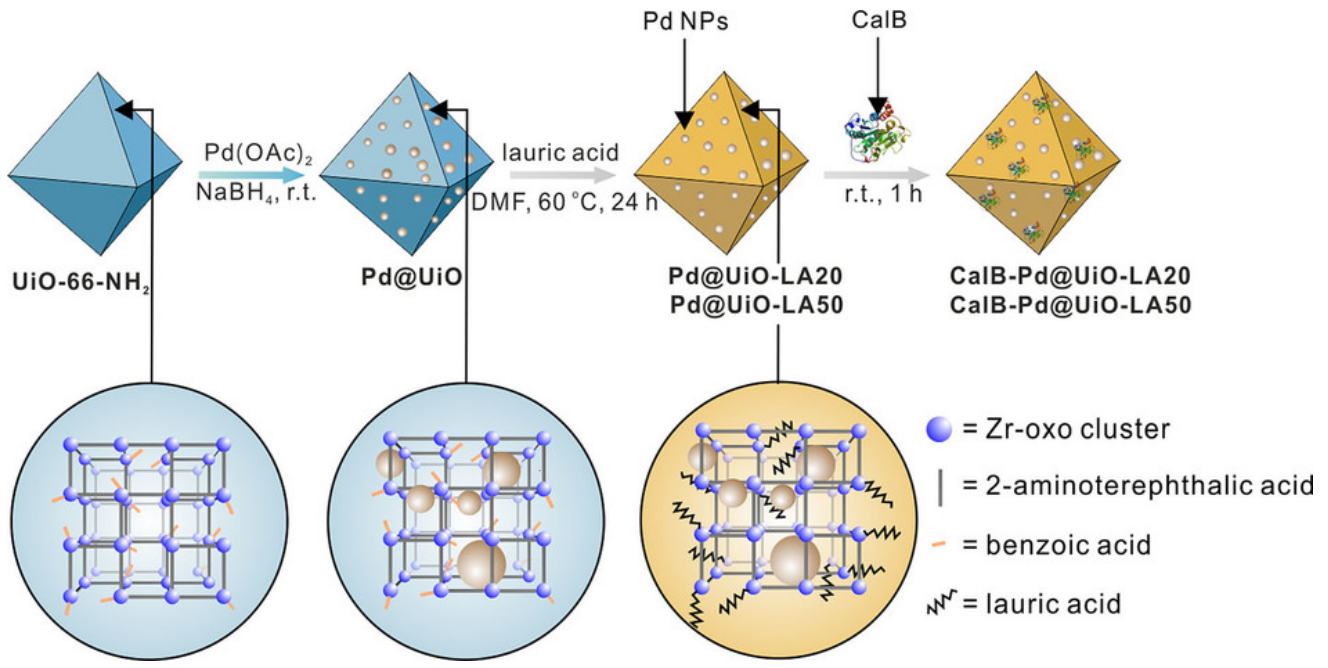

Figure 9. Preparation of a MOF-based CAL-B/Pd catalyst [180]. Reprinted from [180] with permission of John Wiley and Sons.

The strength of hybrid catalyst in chemoenzymatic cascade and the usefulness of MOF as a supporting material were demonstrated in a recent work on the co-immobilization of L-amino acid oxidase (LAAO) and Pt nanoparticles on UiO-66 [181]. LAAO catalyzes the oxidation of alpha-amino acids using $\mathrm{O}_{2}$ as oxidant and FAD as cofactor to give alpha-ketocarboxylic acids and $\mathrm{H}_{2} \mathrm{O}_{2}$ as the byproduct. Because $\mathrm{H}_{2} \mathrm{O}_{2}$ promotes decarboxylation of alpha-keto-carboxylic acids, its removal is required to achieve satisfactory yields. To address this issue, $\mathrm{Wu}$ and co-workers [181] designed a MOF-based hybrid catalyst containing $\mathrm{LAOO}$ and $\mathrm{Pt}$ nanoparticles, in which $\mathrm{Pt}$ was for the decomposing $\mathrm{H}_{2} \mathrm{O}_{2}$ to $\mathrm{O}_{2}$ and water, thus avoiding decarboxylation of the target compound. To avoid mutual inactivation between $\mathrm{Pt}$ and LAOO, a compartmentalization approach was envisaged in which metal nanoparticles would be located inside of UiO-66 structure while enzymes would be adsorbed on the surface. In addition, pore sizes of Angstrom-dimension within the MOF would ensure channeling of $\mathrm{H}_{2} \mathrm{O}_{2}$ from enzyme to metal site, thus allowing for its instant decomposition. This hybrid catalyst was successfully obtained by incorporating $\mathrm{Pt}$ nanoparticles in inside MOF matrix through the addition of Pt nanoparticles to the solution of precursors of UiO-66 to perform coprecipitation and then incubating the resulting Pt-containing MOF (Pt@UiO-66) with LAAO to provide the hybrid catalyst as a MOF with Pt nanoparticles immobilized inside, and enzymes adsorbed on the surface (Pt@UiO66@LAAO) (Figure 10). A hybrid catalyst with optimum metal and enzyme loadings was employed in the oxidation of L-tryptophan to give indole-3-pyruvic acid with $99 \%$ yield, which was found to be far higher than that obtained with the free enzyme (41\%) (Scheme 5). The crucial role of compartmentalization in avoiding inactivation and the porous structure to provide $\mathrm{H}_{2} \mathrm{O}_{2}$ channeling was corroborated by comparative experiments with both catalysts in their free form or immobilized in a non-compartmentalized fashion.

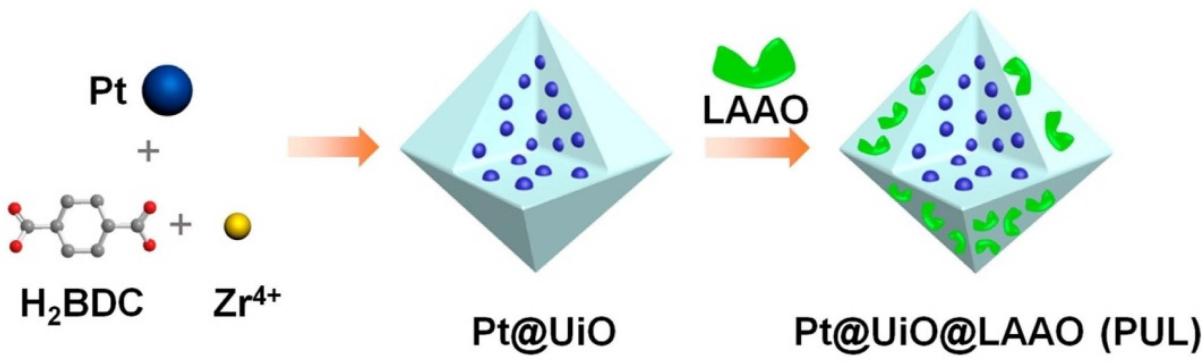

Figure 10. Preparation of a Pt/LAAO catalyst [181]. Reprinted with permission from [181]. Copyright (2020) American Chemical Society. 
<smiles>N[C@@H](Cc1c[nH]c2ccccc12)C(=O)O</smiles>

L-tryptophan

\section{Pt-LAAO hybrid catalyst \\ Tris buffer $(\mathrm{pH} 8.0), 30^{\circ}, 5 \mathrm{~h}$}<smiles>O=C(O)C(=O)Cc1c[nH]c2ccccc12</smiles>

$99.7 \%$ yield

Scheme 5. Preparation of indole-3-pyruvic acid using an hybrid Pt/LAAO catalyst [184].

MOFs have also shown to be useful for co-immobilization of chemo- and biocatalysts in close proximity, resulting in catalytic synergism in a cascade reaction involving enzymatic and metal catalysis as well as Lewis acid catalysis promoted by coordinatively unsaturated metal cations on the MOF structure. The preparation of a MOF-based Pd/lipase hybrid catalyst has been recently reported, in which both catalysts were located inside a single porous of a highly mesoporous MOF ZIF67, a cobalt-based imidazolate framework [182]. In this work, polyvinylpyrrolidone (PVP) was used during the preparation of ZIF67 to achieve proper pore dimensions and defect-rich metal nodes, since PVP is a metal-coordinating bulky polymer able to induce partial disruption of the $\mathrm{Co}(\mathrm{II})$ catenation process. Immobilization of Pd was performed by adding PVP-coated Pd nanocrystal during crystallization and the resulting Pd-containing MOF was then incubated with the lipase CAL-A to provide the MOF-based hybrid catalyst (Figure 11). Because the pore sizes remained in the range of 20-40 nm after Pd immobilization, the lipase could be infiltrated inside the porous instead of being adsorbed on the surface, thus leading to three catalytic species, i.e., enzyme, Pd, and Co(II) within a single nanoreactor space. This multimodal hybrid catalyst was found to be useful in a three-step cascade involving Lewis acid-catalyzed nitroaldol reaction, followed by DKR of the resulting alcohol through Pd-mediated racemization and lipasecatalyzed esterification with vinyl acetate. The reaction was performed with 5 different benzylic aldehydes to give enantiopure esters (ee > 99\%) with excellent yield (96-99\%) in 21-30 h. The hybrid catalyst could be used for at least five runs but not without losses in yield (from 99\% to $86 \%$ ) and enantioselectivity (>80\% ee) and the requirement of slightly longer reaction times probably due to enzyme and Pd leaching.

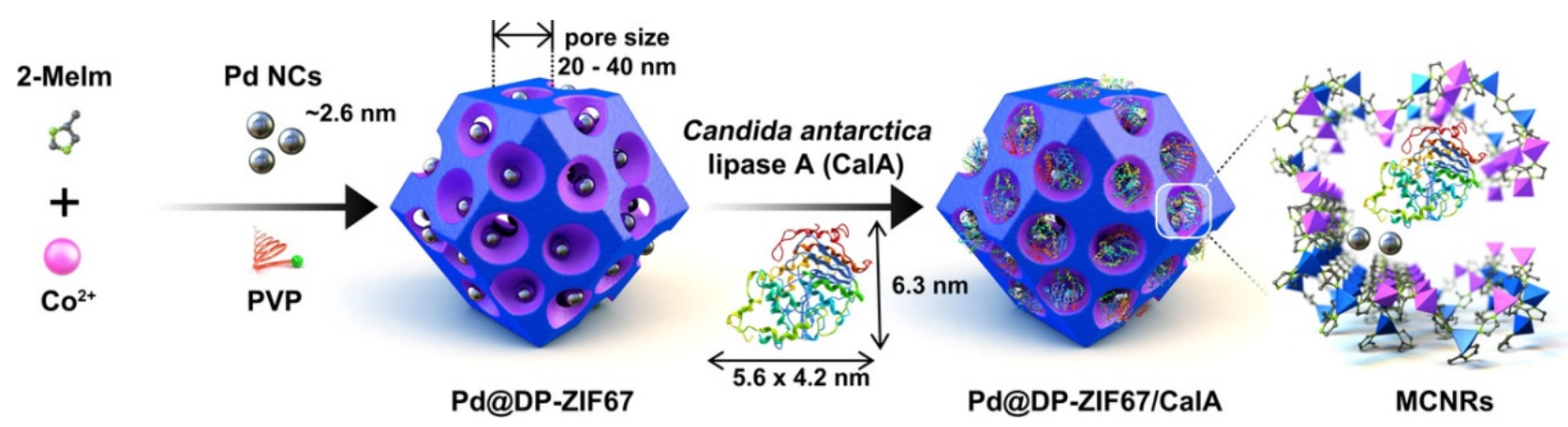

Figure 11. Co-immobilization of Pd and CAL-A into mesopores of ZIF67 [182]. Reprinted from [182] with the permission of John Wiley and Sons.

In addition to the approaches of co-immobilizing metal nanoparticles and enzymes that were discussed herein, catalysts with enzymatic and chemocatalytic activities have also been reported in which the MOF serves as both matrices for enzyme immobilization and as chemical catalysts itself through their metal nodes. For instance, the immobilization of a NAD ${ }^{+}$-dependent alcohol dehydrogenase (ADH) inside a Cu-based MOF HKUST1 through encapsulation has been reported [183]. The HKUST-1 matrix was found to promote regeneration of $\mathrm{NAD}+$ from $\mathrm{NADH}$ at the expense of $\mathrm{H}_{2} \mathrm{O}_{2}$ so that a cofactor regeneration system could be coupled to the oxidation reaction catalyzed by the enzyme. 
The immobilized enzyme was tested for benzyl alcohol oxidation to benzaldehyde, leading to a modest yield $(28 \%)$, which was nevertheless 4.3 higher than the yield obtained with the free enzyme. This work reveals a promising innovative strategy for cofactor regeneration in reactions catalyzed $\mathrm{NAD}^{+}$-dependent enzymes, which remains an important challenge in the field of biocatalytic oxidation of alcohols.

Similar to MOFs, metal-biosurfactant nanocomposites (MBNs) are nanomaterials composed of metal and organic ligands, the latter being biosurfactant molecules. Conversely, MBNs are soft nanomaterials, and their hydrophobic nature makes them suitable for immobilization of hydrophobic catalysts and use in organic solvents. Co-encapsulation of lipase and Shvö catalyst, a Ru-based metal-organic complex used to promote racemization in DKR processes, has been reported as an approach to obtain a hybrid catalyst for chemoenzymatic DKR of alcohols and amines [184]. Co-encapsulation was performed in a single step by mixing enzyme CAL-B, Shvö catalyst, $\mathrm{Co}(\mathrm{II})$, sodium deoxycholate $(\mathrm{NaDC})$, and methyl-imidazol (Mi) and resulted in nanostructures with enzymes as the core and metal-organic catalyst embedded in micropores (Figure 12). This artificial metalloenzyme was found to be more efficient than separated single (bio)catalysts in the DKR of 1-phenylethanol and 1-phenylethylamine in toluene. The estimated short distance of less than $8.5 \mathrm{~nm}$ between the lipase and Shvö catalyst was suggested to improve transportation of reaction intermediates, which could improve efficiency and mitigate the formation of side products, therefore contributing to high yields. In addition, the hybrid catalyst could be reused for five cycles with only slight leaching of enzyme and metal-organic catalyst and loss of less than $30 \%$ of activity in the DKR of 1-phenylethanol, while a loss of more than $50 \%$ of activity was observed for the reaction with 1-phenylethylamine.

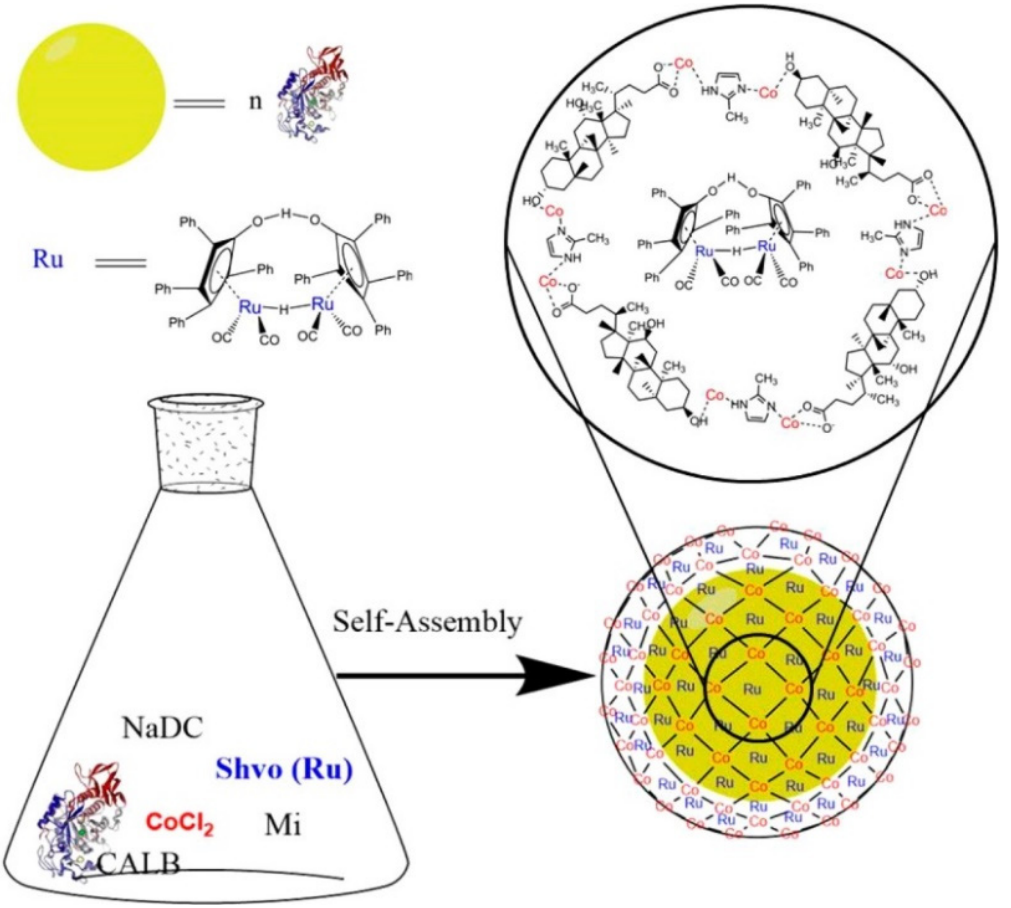

Figure 12. Immobilization of CAL-B and Shvö catalyst in a metal-biosurfactant nanocomposite [184]. $\mathrm{NaDC}=$ sodium deoxycholate, $\mathrm{Mi}=$ methyl-imidazol. Reprinted with permission from [184]. Copyright (2019) American Chemical Society.

The use of carbon nitride $\left(\mathrm{C}_{3} \mathrm{~N}_{4}\right)$ for co-immobilization of Pd nanoparticles and CAL-B has been recently reported [185]. $\mathrm{C}_{3} \mathrm{~N}_{4}$ is a material that can be obtained through the decomposition of dicyanide amide in the air at high temperatures and is composed of repeated tri-s-triazine units that form packed 2D conjugated planes. Wang and co-workers [185] have reported the obtaining of a hybrid catalysts in which Pd nanoparticles were immobilized 
in $\mathrm{C}_{3} \mathrm{~N}_{4}$ through in situ reduction and the resulting material was treated with CAL-B and glutaraldehyde to covalently immobilize the enzyme counterpart. Pd nanoparticles with an approximate diameter of $3.0 \mathrm{~nm}$ were found to be located all over the nanocatalyst whereas lipases were suggested to be immobilized on the surface. A layer of enzymes on the surface was believed to protect the tiny Pd nanoparticles from re-oxidation since the percentage of $\mathrm{Pd}$ (II) was found to be $22 \%$ in Pd/CAL-B hybrid catalyst in contrast to the percentage of $55 \%$ of $\mathrm{Pd}$ (II) encountered in $\mathrm{C}_{3} \mathrm{~N}_{4}$ nanocatalyst containing Pd solely. The hybrid catalyst with optimum Pd and CAL-B loadings of $0.5 \%$ and $2.0 \%$, respectively, was tested for a cascade reaction involving metal-mediated reduction and lipase-catalyzed transesterification in toluene at room temperature for $12 \mathrm{~h}$ to provide benzyl hexanoate from benzaldehyde and ethyl hexanoate in $79 \%$ yield. The hybrid catalyst could be reused four times without leaching of metal, but yield dropped to $26 \%$ mainly due to loss of enzymatic activity.

\section{Conclusions}

The development of catalytic cascade reactions to telescope multistep synthesis is a promising approach to achieve efficient processes with reduced environmental impact. Biocatalytic cascades can gather benefits of both biocatalysis and cascade concept towards greener synthetic methods whereas chemoenzymatic cascades can also count on chemocatalysis versatility to broaden the repertoire of synthetic transformations. The development of (chemo)enzymatic cascade with practical uses and economic viability to reach industrial applications, however, is a challenging task. In this, scenario, co-immobilization of (bio)catalysts in supports might become a crucial technology which enables catalytic synergism and recyclability, leading to higher efficiency and cost-effectiveness. Co-immobilization strategies for the obtaining of multicatalytic materials designed for providing close proximity of catalysts or circumvent incompatibility issues have been recently reported. Nevertheless, optimization of enzyme uses and productivity is still needed to allow for the transition of proofs-of-concept to practical applications. Co-immobilization of catalysts for cascade reactions is a field in development that might be benefitted from multidisciplinary efforts in the next years, including the development of novel materials and studies on the effects of cascade on kinetic and thermodynamics of processes.

Author Contributions: Conceptualization, A.S.d.M., A.H.M., I.I.J. and R.O.M.A.d.S.; writingoriginal draft preparation, A.S.d.M. (Introduction, Conclusions, Section 3), A.A.d.T.J. (Section 2.3), Y.F.X.L. (Section 2.2), A.d.S.F. (Section 2.1), R.W. (Abstract); writing-review and editing, A.S.d.M., A.H.M., I.I.J., R.O.M.A.d.S. and R.W. All authors have read and agreed to the published version of the manuscript.

Funding: This study was funded by the Brazilian government through Fundação Carlos Chagas Filho de Amparo à Pesquisa do Estado do Rio de Janeiro, Grant Number: E-203.267/2017; Conselho Nacional de Desenvolvimento Científico e Tecnológico (BR), Grant Number 429974/2018-3 and by Coordenação de Aperfeiçoamento de Pessoal de Nível Superior. It was also supported by the French government through the Programme Investissement d'Avenir (I-SITE ULNE/ANR-16-IDEX0004ULNE) managed by the Agence Nationale de la Recherche.

Acknowledgments: Authors thank Fundação Carlos Chagas Filho de Amparo à Pesquisa do Estado do Rio de Janeiro for Jovem Cientista do Nosso Estado grant, Conselho Nacional de Desenvolvimento Científico e Tecnológico (BR) for Universal grant, Centrale Lille, the CNRS, and Lille University as well as the Centrale Initiative Foundation, are thanked for their financial contribution. LIA CNRS France-Brazil "Energy and Environment" and M tropole Europ en de Lille (MEL) for "CatBio-Innov" project are also acknowledged.

Conflicts of Interest: The authors declare no conflict of interest.

\section{References}

1. Ni, Y.; Holtmann, D.; Hollmann, F. How Green is Biocatalysis? To Calculate is To Know. ChemCatChem 2014, 6, 930-943. [CrossRef]

2. Turner, N.J.; O'Reilly, E. Biocatalytic retrosynthesis. Nat. Chem. Biol. 2013, 9, 285-288. [CrossRef]

3. De Souza, R.O.M.A.; Miranda, L.S.M.; Bornscheuer, U.T. A Retrosynthesis Approach for Biocatalysis in Organic Synthesis. Chem. A Eur. J. 2017, 23, 12040-12063. [CrossRef] 
4. Sheldon, R.A.; Brady, D. The limits to biocatalysis: Pushing the envelope. Chem. Commun. 2018, 54, 6088-6104. [CrossRef]

5. Bornscheuer, U.T.; Huisman, G.W.; Kazlauskas, R.J.; Lutz, S.; Moore, J.C.; Robins, K. Engineering the third wave of biocatalysis. Nature 2012, 485, 185-194. [CrossRef]

6. Costa, I.C.R.; de Souza, R.O.M.A.; Bornscheuer, U.T. Asymmetric synthesis of serinol-monoesters catalyzed by amine transaminases. Tetrahedron Asymmetry 2017, 28, 1183-1187. [CrossRef]

7. Woodley, J.M. Accelerating the implementation of biocatalysis in industry. Appl. Microbiol. Biotechnol. 2019, 103, 4733-4739. [CrossRef]

8. Sheldon, R.A. Enzyme Immobilization: The Quest for Optimum Performance. Adv. Synth. Catal. 2007, 349, 1289-1307. [CrossRef]

9. Sheldon, R.A.; van Pelt, S. Enzyme immobilisation in biocatalysis: Why, what and how. Chem. Soc. Rev. 2013, 42, 6223-6235. [CrossRef]

10. Schrittwieser, J.H.; Velikogne, S.; Hall, M.; Kroutil, W. Artificial Biocatalytic Linear Cascades for Preparation of Organic Molecules. Chem. Rev. 2018, 118, 270-348. [CrossRef] [PubMed]

11. Cao, L.; van Langen, L.; Sheldon, R.A. Immobilised enzymes: Carrier-bound or carrier-free? Curr. Opin. Biotechnol. 2003, 14, 387-394. [CrossRef]

12. Schoffelen, S.; van Hest, J.C.M. Chemical approaches for the construction of multi-enzyme reaction systems. Curr. Opin. Struct. Biol. 2013, 23, 613-621. [CrossRef] [PubMed]

13. Losada-Garcia, N.; Cabrera, Z.; Urrutia, P.; Garcia-Sanz, C.; Andreu, A.; Palomo, J.M. Recent Advances in Enzymatic and Chemoenzymatic Cascade Processes. Catalysts 2020, 10, 1258. [CrossRef]

14. Ricca, E.; Brucher, B.; Schrittwieser, J.H. Multi-enzymatic cascade reactions: Overview and perspectives. Adv. Synth. Catal. 2011, 353, 2239-2262. [CrossRef]

15. Schmid-Dannert, C.; López-Gallego, F. Advances and opportunities for the design of self-sufficient and spatially organized cell-free biocatalytic systems. Curr. Opin. Chem. Biol. 2019, 49, 97-104. [CrossRef]

16. Ren, S.; Li, C.; Jiao, X.; Jia, S.; Jiang, Y.; Bilal, M.; Cui, J. Recent progress in multienzymes co-immobilization and multienzyme system applications. Chem. Eng. J. 2019, 373, 1254-1278. [CrossRef]

17. France, S.P.; Hepworth, L.J.; Turner, N.J.; Flitsch, S.L. Constructing Biocatalytic Cascades: In Vitro and in Vivo Approaches to de Novo Multi-Enzyme Pathways. ACS Catal. 2017, 7, 710-724. [CrossRef]

18. Zhao, F.; Masci, D.; Tomarelli, E.; Castagnolo, D. Biocatalytic and Chemo-Enzymatic Approaches for the Synthesis of Heterocycles. Synthesis 2020, 52, 2948-2961. [CrossRef]

19. Denard, C.A.; Hartwig, J.F.; Zhao, H. Multistep One-Pot Reactions Combining Biocatalysts and Chemical Catalysts for Asymmetric Synthesis. ACS Catal. 2013, 3, 2856-2864. [CrossRef]

20. Liu, Y.; Liu, P.; Gao, S.; Wang, Z.; Luan, P.; González-Sabín, J.; Jiang, Y. Construction of chemoenzymatic cascade reactions for bridging chemocatalysis and Biocatalysis: Principles, strategies and prospective. Chem. Eng. J. 2020, 420, 127659. [CrossRef]

21. Kourist, R.; González-Sabín, J. Non-Conventional Media as Strategy to Overcome the Solvent Dilemma in Chemoenzymatic Tandem Catalysis. Chem CatChem 2020, 12, 1903-1912. [CrossRef]

22. Schmidt, S.; Castiglione, K.; Kourist, R. Overcoming the Incompatibility Challenge in Chemoenzymatic and Multi-Catalytic Cascade Reactions. Chem. A Eur. J. 2018, 24, 1755-1768. [CrossRef]

23. Heuson, E.; Dumeignil, F. The various levels of integration of chemo- and bio-catalysis towards hybrid catalysis. Catal. Sci. Technol. 2020, 10, 7082-7100. [CrossRef]

24. Li, X.; Cao, X.; Xiong, J.; Ge, J. Enzyme-Metal Hybrid Catalysts for Chemoenzymatic Reactions. Small 2020, 16, 1902751. [CrossRef]

25. Debecker, D.P.; Smeets, V.; Van der Verren, M.; Meersseman, A.H.; Kinnaer, M.; Devred, F. Hybrid chemoenzymatic heterogeneous catalysts. Curr. Opin. Green Sustain. Chem. 2021, 28, 100437. [CrossRef]

26. Hwang, E.T.; Lee, S. Multienzymatic Cascade Reactions via Enzyme Complex by Immobilization. ACS Catal. 2019, 9, 4402-4425. [CrossRef]

27. Hirata, D.B.; Albuquerque, T.L.; Rueda, N.; Virgen-Ortíz, J.J.; Tacias-Pascacio, V.G.; Fernandez-Lafuente, R. Evaluation of different immobilized lipases in transesterification reactions using tributyrin: Advantages of the heterofunctional octyl agarose beads. $J$. Mol. Catal. B Enzym. 2016, 133, 117-123. [CrossRef]

28. Kuo, C.-H.; Shieh, C.-J. Biocatalytic Process Optimization. Catalysts 2020, 10, 1303. [CrossRef]

29. Cantone, S.; Ferrario, V.; Corici, L.; Ebert, C.; Fattor, D.; Spizzo, P.; Gardossi, L. Efficient immobilisation of industrial biocatalysts: Criteria and constraints for the selection of organic polymeric carriers and immobilisation methods. Chem. Soc. Rev. 2013, 42, 6262-6276. [CrossRef]

30. Gomes-Ruffi, C.R.; da Cunha, R.H.; Almeida, E.L.; Chang, Y.K.; Steel, C.J. Effect of the emulsifier sodium stearoyl lactylate and of the enzyme maltogenic amylase on the quality of pan bread during storage. LWT 2012, 49, 96-101. [CrossRef]

31. Homaei, A.A.; Sariri, R.; Vianello, F.; Stevanato, R. Enzyme immobilization: An update. J. Chem. Biol. 2013, 6, 185-205. [CrossRef]

32. Hartmann, M. Ordered Mesoporous Materials for Bioadsorption and Biocatalysis. Chem. Mater. 2005, 17, 4577-4593. [CrossRef]

33. Kallenberg, A.I.; van Rantwijk, F.; Sheldon, R.A. Immobilization of Penicillin G Acylase: The Key to Optimum Performance. Adv. Synth. Catal. 2005, 347, 905-926. [CrossRef]

34. Pierre, A.C. The sol-gel encapsulation of enzymes. Biocatal. Biotransform. 2004, 22, 145-170. [CrossRef]

35. Gutarra, M.L.E.; Miranda, L.S.M.; de Souza, R.O.M.A. Enzyme Immobilization for Organic Synthesis. In Organic Synthesis Using Biocatalysis; Elsevier: Amsterdam, The Netherlands, 2016; pp. 99-126. 
36. Garcia-Galan, C.; Berenguer-Murcia, Á.; Fernandez-Lafuente, R.; Rodrigues, R.C. Potential of Different Enzyme Immobilization Strategies to Improve Enzyme Performance. Adv. Synth. Catal. 2011, 353, 2885-2904. [CrossRef]

37. Tran, D.N.; Balkus, K.J. Perspective of Recent Progress in Immobilization of Enzymes. ACS Catal. 2011, 1, 956-968. [CrossRef]

38. Oliveira, F.L.; França, S.A.; Castro, A.M.; Alves de Souza, R.O.M.; Esteves, P.M.; Gonçalves, R.S.B. Enzyme Immobilization in Covalent Organic Frameworks: Strategies and Applications in Biocatalysis. Chempluschem 2020, 85, 2051-2066. [CrossRef]

39. Scherer, R.P.; Dallago, R.L.; Penna, F.G.; Bertella, F.; de Oliveira, D.; de Oliveira, J.V.; Pergher, S.B.C. Influence of process parameters on the immobilization of commercial porcine pancreatic lipase using three low-cost supports. Biocatal. Agric. Biotechnol. 2012, 1, 290-294. [CrossRef]

40. Gérardin, C.; Reboul, J.; Bonne, M.; Lebeau, B. Ecodesign of ordered mesoporous silica materials. Chem. Soc. Rev. 2013, 42, 4217-4255. [CrossRef] [PubMed]

41. Liang, J.F.; Li, Y.T.; Yang, V.C. Biomedical Application of Immobilized Enzymes. J. Pharm. Sci. 2000, 89, 979-990. [CrossRef]

42. D'Souza, S.F. Immobilization and Stabilization of Biomaterials for Biosensor Applications. Appl. Biochem. Biotechnol. 2001, 96, 225-238. [CrossRef]

43. Wu, L.-C.; Cheng, C.-M. Flow-injection enzymatic analysis for glycerol and triacylglycerol. Anal. Biochem. 2005, 346, 234-240. [CrossRef]

44. Arroyo, M.; de la Mata, I.; Acebal, C.; Pilar Castillón, M. Biotechnological applications of penicillin acylases: State-of-the-art. Appl. Microbiol. Biotechnol. 2003, 60, 507-514. [CrossRef] [PubMed]

45. Girelli, A.M.; Mattei, E. Application of immobilized enzyme reactor in on-line high performance liquid chromatography: A review. J. Chromatogr. B 2005, 819, 3-16. [CrossRef]

46. Taylor, R.F. Protein Immobilization; Dekker, M., Ed.; Taylor \& Francis: New York, NY, USA, 1991.

47. Rao, S.V.; Anderson, K.W.; Bachas, L.G. Oriented immobilization of proteins. Mikrochim. Acta 1998, 128, 127-143. [CrossRef]

48. Wilchek, M.; Miron, T. Oriented versus random protein immobilization. J. Biochem. Biophys. Methods 2003, 55, 67-70. [CrossRef]

49. Turková, J. Oriented immobilization of biologically active proteins as a tool for revealing protein interactions and function. J. Chromatogr. B Biomed. Sci. Appl. 1999, 722, 11-31. [CrossRef]

50. Wilchek, M.; Miron, T.; Kohn, J.B.T.-M. in E. Affinity chromatography. In Part C: Enzyme Purification and Related Techniques; Academic Press: Cambridge, MA, USA, 1984; Volume 104, pp. 3-55. ISBN 0076-6879.

51. Carvalho, N.B.; Lima, Á.S.; Soares, C.M.F. Use of Modified Silicas for Lipase Immobilization. Quim. Nova 2014, 38, 399-409. [CrossRef]

52. Sun, Q.; Fu, C.-W.; Aguila, B.; Perman, J.; Wang, S.; Huang, H.-Y.; Xiao, F.-S.; Ma, S. Pore Environment Control and Enhanced Performance of Enzymes Infiltrated in Covalent Organic Frameworks. J. Am. Chem. Soc. 2018, 140, 984-992. [CrossRef] [PubMed]

53. Wu, M.; He, Q.; Shao, Q.; Zuo, Y.; Wang, F.; Ni, H. Preparation and Characterization of Monodispersed Microfloccules of TiO2 Nanoparticles with Immobilized Multienzymes. ACS Appl. Mater. Interfaces 2011, 3, 3300-3307. [CrossRef]

54. Le, M.; Means, G.E. NAD+/NADH recycling by coimmobilized lactate dehydrogenase and glutamate dehydrogenase. Enzyme Microb. Technol. 1998, 23, 49-57. [CrossRef]

55. Liu, X.; Du, X.; Feng, J.; Wu, M.-B.; Lin, J.; Guan, J.; Wang, T.; Zhang, Z. Co-immobilization of Short-Chain Dehydrogenase/Reductase and Glucose Dehydrogenase for the Efficient Production of ( \pm )-Ethyl Mandelate. Catal. Lett. 2019, 149, 1710-1720. [CrossRef]

56. Bachosz, K.; Synoradzki, K.; Staszak, M.; Pinelo, M.; Meyer, A.S.; Zdarta, J.; Jesionowski, T. Bioconversion of xylose to xylonic acid via co-immobilized dehydrogenases for conjunct cofactor regeneration. Bioorg. Chem. 2019, 93, 102747. [CrossRef]

57. Bachosz, K.; Zdarta, J.; Marczak, Ł.; Błażewicz, J.; Jesionowski, T. A highly effective approach to cofactor regeneration and subsequent membrane separation of bioconversion products: Kinetic parameters and effect of process conditions. Bioresour. Technol. Rep. 2020, 9, 100365. [CrossRef]

58. Luo, J.; Meyer, A.S.; Mateiu, R.V.; Pinelo, M. Cascade catalysis in membranes with enzyme immobilization for multi-enzymatic conversion of $\mathrm{CO}_{2}$ to methanol. N. Biotechnol. 2015, 32, 319-327. [CrossRef]

59. Zhong, C.; Duić, B.; Bolivar, J.M.; Nidetzky, B. Three-Enzyme Phosphorylase Cascade Immobilized on Solid Support for Biocatalytic Synthesis of Cello-oligosaccharides. ChemCatChem 2020, 12, 1350-1358. [CrossRef]

60. Valikhani, D.; Bolivar, J.M.; Dennig, A.; Nidetzky, B. A tailor-made, self-sufficient and recyclable monooxygenase catalyst based on coimmobilized cytochrome P450 BM3 and glucose dehydrogenase. Biotechnol. Bioeng. 2018, 115, 2416-2425. [CrossRef]

61. Rocha-Martín, J.; de las Rivas, B.; Muñoz, R.; Guisán, J.M.; López-Gallego, F. Rational Co-Immobilization of Bi-Enzyme Cascades on Porous Supports and their Applications in Bio-Redox Reactions with In Situ Recycling of Soluble Cofactors. ChemCatChem 2012, 4, 1279-1288. [CrossRef]

62. Velasco-Lozano, S.; Santiago-Arcos, J.; Mayoral, J.A.; López-Gallego, F. Co-immobilization and Colocalization of Multi-Enzyme Systems for the Cell-Free Biosynthesis of Aminoalcohols. ChemCatChem 2020, 12, 3030-3041. [CrossRef]

63. Peirce, S.; Virgen-Ortíz, J.J.; Tacias-Pascacio, V.G.; Rueda, N.; Bartolome-Cabrero, R.; Fernandez-Lopez, L.; Russo, M.E.; Marzocchella, A.; Fernandez-Lafuente, R. Development of simple protocols to solve the problems of enzyme coimmobilization. Application to coimmobilize a lipase and a $\beta$-galactosidase. RSC Adv. 2016, 6, 61707-61715. [CrossRef]

64. Mallin, H.; Wulf, H.; Bornscheuer, U.T. A self-sufficient Baeyer-Villiger biocatalysis system for the synthesis of $\varepsilon$-caprolactone from cyclohexanol. Enzyme Microb. Technol. 2013, 53, 283-287. [CrossRef] 
65. Delgove, M.A.F.; Valencia, D.; Solé, J.; Bernaerts, K.V.; De Wildeman, S.M.A.; Guillén, M.; Álvaro, G. High performing immobilized Baeyer-Villiger monooxygenase and glucose dehydrogenase for the synthesis of $\varepsilon$-caprolactone derivative. Appl. Catal. A Gen. 2019, 572, 134-141. [CrossRef]

66. Solé, J.; Caminal, G.; Schürmann, M.; Álvaro, G.; Guillén, M. Co-immobilization of P450 BM3 and glucose dehydrogenase on different supports for application as a self-sufficient oxidative biocatalyst. J. Chem. Technol. Biotechnol. 2019, 94, 244-255. [CrossRef]

67. Giannakopoulou, A.; Patila, M.; Spyrou, K.; Chalmpes, N.; Zarafeta, D.; Skretas, G.; Gournis, D.; Stamatis, H. Development of a Four-Enzyme Magnetic Nanobiocatalyst for Multi-Step Cascade Reactions. Catalysts 2019, 9, 995. [CrossRef]

68. Torabizadeh, H.; Montazeri, E. Nano co-immobilization of $\alpha$-amylase and maltogenic amylase by nanomagnetic combi-cross-linked enzyme aggregates method for maltose production from corn starch. Carbohydr. Res. 2020, 488, 107904. [CrossRef] [PubMed]

69. Rezaei, S.; Landarani-Isfahani, A.; Moghadam, M.; Tangestaninejad, S.; Mirkhani, V.; Mohammadpoor-Baltork, I. Development of a novel bi-enzymatic silver dendritic hierarchical nanostructure cascade catalytic system for efficient conversion of starch into gluconic acid. Chem. Eng. J. 2019, 356, 423-435. [CrossRef]

70. Chen, R.; Wei, Q.; Wei, X.; Liu, Y.; Zhang, X.; Chen, X.; Yin, X.; Xie, T. Stable and efficient immobilization of bi-enzymatic NADPH cofactor recycling system under consecutive microwave irradiation. PLoS ONE 2020, 15, e0242564. [CrossRef]

71. Kirupa, S.M.; Ravikumar, R.; Naresh, K.M.; Sivakumar, U. Development of co-immobilized tri-enzyme biocatalytic system for one-pot pretreatment of four different perennial lignocellulosic biomass and evaluation of their bioethanol production potential. Bioresour. Technol. 2018, 269, 227-236. [CrossRef]

72. El-Zahab, B.; Jia, H.; Wang, P. Enabling multienzyme biocatalysis using nanoporous materials. Biotechnol. Bioeng. 2004, 87, 178-183. [CrossRef] [PubMed]

73. Küchler, A.; Adamcik, J.; Mezzenga, R.; Schlüter, A.D.; Walde, P. Enzyme immobilization on silicate glass through simple adsorption of dendronized polymer-enzyme conjugates for localized enzymatic cascade reactions. RSC Adv. 2015, 5, 44530-44544. [CrossRef]

74. Zhou, X.; Liu, Y.; Yuan, Q.; Liang, H. Preparation of multi-enzyme co-immobilized nanoparticles by bis-aryl hydrazone bond conjugation. Biotechnol. Appl. Biochem. 2016, 63, 214-219. [CrossRef] [PubMed]

75. Peng, F.; Ou, X.-Y.; Guo, Z.-W.; Zeng, Y.-J.; Zong, M.-H.; Lou, W.-Y. Co-immobilization of multiple enzymes by self-assembly and chemical crosslinking for cofactor regeneration and robust biocatalysis. Int. J. Biol. Macromol. 2020, 162, 445-453. [CrossRef]

76. Tan, C.Y.; Hirakawa, H.; Suzuki, R.; Haga, T.; Iwata, F.; Nagamune, T. Immobilization of a Bacterial Cytochrome P450 Monooxygenase System on a Solid Support. Angew. Chemie Int. Ed. 2016, 55, 15002-15006. [CrossRef] [PubMed]

77. Zhang, Y.; Yong, Y.; Ge, J.; Liu, Z. Lectin Agglutinated Multienzyme Catalyst with Enhanced Substrate Affinity and Activity. ACS Catal. 2016, 6, 3789-3795. [CrossRef]

78. Hu, X.; Liu, L.; Chen, D.; Wang, Y.; Zhang, J.; Shao, L. Co-expression of the recombined alcohol dehydrogenase and glucose dehydrogenase and cross-linked enzyme aggregates stabilization. Bioresour. Technol. 2017, 224, 531-535. [CrossRef]

79. Aranaz, I.; Acosta, N.; Férnandez-Valle, M.E.; Heras, A. Optimization of d-amino acid production catalyzed by immobilized multi-enzyme system in polyelectrolyte complex gel capsules. J. Mol. Catal. B Enzym. 2015, 121, 45-52. [CrossRef]

80. McKenna, S.M.; Mines, P.; Law, P.; Kovacs-Schreiner, K.; Birmingham, W.R.; Turner, N.J.; Leimkühler, S.; Carnell, A.J. The continuous oxidation of HMF to FDCA and the immobilisation and stabilisation of periplasmic aldehyde oxidase (PaoABC). Green Chem. 2017, 19, 4660-4665. [CrossRef]

81. Long, J.; Pan, T.; Xie, Z.; Xu, X.; Jin, Z. Effective production of lactosucrose using $\beta$-fructofuranosidase and glucose oxidase co-immobilized by sol-gel encapsulation. Food Sci. Nutr. 2019, 7, 3302-3316. [CrossRef]

82. Long, J.; Pan, T.; Xie, Z.; Xu, X.; Jin, Z. Co-immobilization of $\beta$-fructofuranosidase and glucose oxidase improves the stability of Bi-enzymes and the production of lactosucrose. LWT 2020, 128, 109460. [CrossRef]

83. Chen, W.-H.; Vázquez-González, M.; Zoabi, A.; Abu-Reziq, R.; Willner, I. Biocatalytic cascades driven by enzymes encapsulated in metal-organic framework nanoparticles. Nat. Catal. 2018, 1, 689-695. [CrossRef]

84. Zhu, D.; Ao, S.; Deng, H.; Wang, M.; Qin, C.; Zhang, J.; Jia, Y.; Ye, P.; Ni, H. Ordered Coimmobilization of a Multienzyme Cascade System with a Metal Organic Framework in a Membrane: Reduction of $\mathrm{CO}_{2}$ to Methanol. ACS Appl. Mater. Interfaces 2019, 11, 33581-33588. [CrossRef] [PubMed]

85. Ren, S.; Wang, Z.; Bilal, M.; Feng, Y.; Jiang, Y.; Jia, S.; Cui, J. Co-immobilization multienzyme nanoreactor with co-factor regeneration for conversion of $\mathrm{CO}_{2}$. Int. J. Biol. Macromol. 2020, 155, 110-118. [CrossRef] [PubMed]

86. Ji, X.; Su, Z.; Wang, P.; Ma, G.; Zhang, S. Tethering of Nicotinamide Adenine Dinucleotide Inside Hollow Nanofibers for HighYield Synthesis of Methanol from Carbon Dioxide Catalyzed by Coencapsulated Multienzymes. ACS Nano 2015, 9, 4600-4610. [CrossRef] [PubMed]

87. Klermund, L.; Poschenrieder, S.T.; Castiglione, K. Biocatalysis in Polymersomes: Improving Multienzyme Cascades with Incompatible Reaction Steps by Compartmentalization. ACS Catal. 2017, 7, 3900-3904. [CrossRef]

88. Jesionowski, T.; Zdarta, J.; Krajewska, B. Enzyme immobilization by adsorption: A review. Adsorption 2014, 20, 801-821. [CrossRef]

89. Hartmann, M.; Kostrov, X. Immobilization of enzymes on porous silicas-Benefits and challenges. Chem. Soc. Rev. 2013, 42, 6277-6289. [CrossRef]

90. Mokhtar, N.F.; Rahman, R.N.Z.R.A.; Muhd, N.N.D.; Mohd, S.F.; Mohamad, A.M.S. The Immobilization of Lipases on Porous Support by Adsorption and Hydrophobic Interaction Method. Catalysts 2020, 10, 744. [CrossRef] 
91. Amirnejat, S.; Movahedi, F.; Masrouri, H.; Mohadesi, M.; Kassaee, M.Z. Silica nanoparticles immobilized benzoylthiourea ferrous complex as an efficient and reusable catalyst for one-pot synthesis of benzopyranopyrimidines. J. Mol. Catal. A Chem. 2013, 378, 135-141. [CrossRef]

92. Basri, M.; Kassim, M.A.; Mohamad, R.; Ariff, A.B. Optimization and kinetic study on the synthesis of palm oil ester using Lipozyme TL IM. J. Mol. Catal. B Enzym. 2013, 85-86, 214-219. [CrossRef]

93. Beck, J.S.; Vartuli, J.C.; Roth, W.J.; Leonowicz, M.E.; Kresge, C.T.; Schmitt, K.D.; Chu, C.T.W.; Olson, D.H.; Sheppard, E.W.; McCullen, S.B.; et al. A new family of mesoporous molecular sieves prepared with liquid crystal templates. J. Am. Chem. Soc. 1992, 114, 10834-10843. [CrossRef]

94. Jaros, D.; Rohm, H. Enzymes Exogenous to Milk in Dairy Technology I Transglutaminase. Encycl. Dairy Sci. 2011, 297-300. [CrossRef]

95. Xu, Y.; Zhou, G.; Wu, C.; Li, T.; Song, H. Improving adsorption and activation of the lipase immobilized in amino-functionalized ordered mesoporous SBA-15. Solid State Sci. 2011, 13, 867-874. [CrossRef]

96. Yang, J.; Hu, Y.; Jiang, L.; Zou, B.; Jia, R.; Huang, H. Enhancing the catalytic properties of porcine pancreatic lipase by immobilization on SBA-15 modified by functionalized ionic liquid. Biochem. Eng. J. 2013, 70, 46-54. [CrossRef]

97. Zou, B.; Song, C.; Xu, X.; Xia, J.; Huo, S.; Cui, F. Enhancing stabilities of lipase by enzyme aggregate coating immobilized onto ionic liquid modified mesoporous materials. Appl. Surf. Sci. 2014, 311, 62-67. [CrossRef]

98. Ramani, K.; Karthikeyan, S.; Boopathy, R.; Kennedy, L.J.; Mandal, A.B.; Sekaran, G. Surface functionalized mesoporous activated carbon for the immobilization of acidic lipase and their application to hydrolysis of waste cooked oil: Isotherm and kinetic studies. Process Biochem. 2012, 47, 435-445. [CrossRef]

99. Fernandez-Lafuente, R. Lipase from Thermomyces lanuginosus: Uses and prospects as an industrial biocatalyst. J. Mol. Catal. B Enzym. 2010, 62, 197-212. [CrossRef]

100. Mozhaev, V.V.; Melik-nubarov, N.S.; Sergeeva, M.V.; Šikšnis, V.; Martinek, K. Strategy for Stabilizing Enzymes Part One: Increasing Stability of Enzymes via their Multi-Point Interaction with a Support. Biocatalysis 1990, 3, 179-187. [CrossRef]

101. Agostinelli, E.; Belli, F.; Tempera, G.; Mura, A.; Floris, G.; Toniolo, L.; Vavasori, A.; Fabris, S.; Momo, F.; Stevanato, R. Polyketone polymer: A new support for direct enzyme immobilization. J. Biotechnol. 2007, 127, 670-678. [CrossRef]

102. Orrego, C.E.; Salgado, N.; Valencia, J.S.; Giraldo, G.I.; Giraldo, O.H.; Cardona, C.A. Novel chitosan membranes as support for lipases immobilization: Characterization aspects. Carbohydr. Polym. 2010, 79, 9-16. [CrossRef]

103. Thyparambil, A.A.; Wei, Y.; Latour, R.A. Experimental characterization of adsorbed protein orientation, conformation, and bioactivity. Biointerphases 2015, 10, 19002. [CrossRef]

104. Gayet, J.-C.; Fortier, G. Drug Release from New Bioartificial Hydrogel. Artif. Cells Blood Substit. Biotechnol. 1995, $23,605-611$. [CrossRef]

105. Cao, S.-L.; Huang, Y.-M.; Li, X.-H.; Xu, P.; Wu, H.; Li, N.; Lou, W.-Y.; Zong, M.-H. Preparation and Characterization of Immobilized Lipase from Pseudomonas Cepacia onto Magnetic Cellulose Nanocrystals. Sci. Rep. 2016, 6, 20420. [CrossRef]

106. Souza, C.J.F.; Garcia-Rojas, E.E.; Favaro-Trindade, C.S. Lactase ( $\beta$-galactosidase) immobilization by complex formation: Impact of biopolymers on enzyme activity. Food Hydrocoll. 2018, 83, 88-96. [CrossRef]

107. Rodrigues, R.C.; Barbosa, O.; Ortiz, C.; Berenguer-Murcia, Á.; Torres, R.; Fernandez-Lafuente, R. Amination of enzymes to improve biocatalyst performance: Coupling genetic modification and physicochemical tools. RSC Adv. 2014, 4, 38350-38374 [CrossRef]

108. Elias, N.; Chandren, S.; Razak, F.I.A.; Jamalis, J.; Widodo, N.; Wahab, R.A. Characterization, optimization and stability studies on Candida rugosa lipase supported on nanocellulose reinforced chitosan prepared from oil palm biomass. Int. J. Biol. Macromol. 2018, 114, 306-316. [CrossRef] [PubMed]

109. Pessela, B.C.C.; Fernández-Lafuente, R.; Fuentes, M.; Vián, A.; García, J.L.; Carrascosa, A.V.; Mateo, C.; Guisán, J.M. Reversible immobilization of a thermophilic $\beta$-galactosidase via ionic adsorption on PEI-coated Sepabeads. Enzyme Microb. Technol. 2003, 32, 369-374. [CrossRef]

110. Fuentes, M.; Pessela, B.C.C.; Maquiese, J.V.; Ortiz, C.; Segura, R.L.; Palomo, J.M.; Abian, O.; Torres, R.; Mateo, C.; FernándezLafuente, R.; et al. Reversible and Strong Immobilization of Proteins by Ionic Exchange on Supports Coated with Sulfate-Dextran. Biotechnol. Prog. 2004, 20, 1134-1139. [CrossRef]

111. Orrego, H.A.; Romero-Fernández, M.; Millán-Linares, M.; Yust, M.; Guisán, J.; Rocha-Martin, J. Stabilization of Enzymes by Multipoint Covalent Attachment on Aldehyde-Supports: 2-Picoline Borane as an Alternative Reducing Agent. Catalysts 2018, 8 , 333. [CrossRef]

112. Mohammadi, M.; Ashjari, M.; Garmroodi, M.; Yousefi, M.; Karkhane, A.A. The use of isocyanide-based multicomponent reaction for covalent immobilization of Rhizomucor miehei lipase on multiwall carbon nanotubes and graphene nanosheets. RSC Adv. 2016, 6, 72275-72285. [CrossRef]

113. Li, X.; Wang, X.; Ye, G.; Xia, W.; Wang, X. Polystyrene-based diazonium salt as adhesive: A new approach for enzyme immobilization on polymeric supports. Polymer 2010, 51, 860-867. [CrossRef]

114. Barbosa, O.; Ortiz, C.; Berenguer-Murcia, Á.; Torres, R.; Rodrigues, R.C.; Fernandez-Lafuente, R. Glutaraldehyde in bio-catalysts design: A useful crosslinker and a versatile tool in enzyme immobilization. RSC Adv. 2014, 4, 1583-1600. [CrossRef]

115. Veronese, F.M.; Morpurgo, M. Bioconjugation in pharmaceutical chemistry. Farmaco 1999, 54, 497-516. [CrossRef] 
116. Mateo, C.; Abian, O.; Fernandez-Lafuente, R.; Guisan, J.M. Reversible enzyme immobilization via a very strong and nondistorting ionic adsorption on support-polyethylenimine composites. Biotechnol. Bioeng. 2000, 68, 98-105. [CrossRef]

117. Rubentheren, V.; Ward, T.A.; Chee, C.Y.; Tang, C.K. Processing and analysis of chitosan nanocomposites reinforced with chitin whiskers and tannic acid as a crosslinker. Carbohydr. Polym. 2015, 115, 379-387. [CrossRef]

118. Manan, F.M.A.; Attan, N.; Zakaria, Z.; Keyon, A.S.A.; Wahab, R.A. Enzymatic esterification of eugenol and benzoic acid by a novel chitosan-chitin nanowhiskers supported Rhizomucor miehei lipase: Process optimization and kinetic assessments. Enzyme Microb. Technol. 2018, 108, 42-52. [CrossRef]

119. Elias, N.; Chandren, S.; Attan, N.; Mahat, N.A.; Razak, F.I.A.; Jamalis, J.; Wahab, R.A. Structure and properties of oil palm-based nanocellulose reinforced chitosan nanocomposite for efficient synthesis of butyl butyrate. Carbohydr. Polym. 2017, 176, 281-292 [CrossRef]

120. Van de Velde, F.; Lourenço, N.D.; Pinheiro, H.M.; Bakker, M. Carrageenan: A Food-Grade and Biocompatible Support for Immobilisation Techniques. Adv. Synth. Catal. 2002, 344, 815-835. [CrossRef]

121. Jackson, E.; Correa, S.; Betancor, L. Cellulose-Based Nanosupports for Enzyme Immobilization. In Polymers and Polymeric Composites: A Reference Series; Springer: Cham, Switzerland, 2019; pp. 1235-1253.

122. Lin, N.; Dufresne, A. Nanocellulose in biomedicine: Current status and future prospect. Eur. Polym. J. 2014, 59, 302-325. [CrossRef]

123. Khan, A.A.; Akhtar, S.; Husain, Q. Direct immobilization of polyphenol oxidases on Celite 545 from ammonium sulphate fractionated proteins of potato (Solanum tuberosum). J. Mol. Catal. B Enzym. 2006, 40, 58-63. [CrossRef]

124. Sulaiman, S.; Mokhtar, M.N.; Naim, M.N.; Baharuddin, A.S.; Salleh, M.A.M.; Sulaiman, A. Development of Cellulose Nano fibre (CNF) Derived from Kenaf Bast Fibre and its Potential in Enzyme Immobilization Support. Malays. J. Anal. Sci. 2016, 20, 309-317. [CrossRef]

125. Luo, X.; Zhang, L. Immobilization of Penicillin G Acylase in Epoxy-Activated Magnetic Cellulose Microspheres for Improvement of Biocatalytic Stability and Activities. Biomacromolecules 2010, 11, 2896-2903. [CrossRef]

126. No, H.K.; Meyers, S.P. Preparation and Characterization of Chitin and Chitosan-A Review. J. Aquat. Food Prod. Technol. 1995, 4, 27-52. [CrossRef]

127. Elias, N.; Wahab, R.A.; Chandren, S.; Abdul Razak, F.I.; Jamalis, J. Effect of operative variables and kinetic study of butyl butyrate synthesis by Candida rugosa lipase activated by chitosan-reinforced nanocellulose derived from raw oil palm leaves. Enzyme Microb. Technol. 2019, 130, 109367. [CrossRef]

128. Wan Ngah, W.S.; Teong, L.C.; Hanafiah, M.A.K.M. Adsorption of dyes and heavy metal ions by chitosan composites: A review. Carbohydr. Polym. 2011, 83, 1446-1456. [CrossRef]

129. Abd Manan, F.M.; Attan, N.; Zakaria, Z.; Mahat, N.A.; Abdul, W.R. Insight into the Rhizomucor miehei lipase supported on chitosan-chitin nanowhiskers assisted esterification of eugenol to eugenyl benzoate. J. Biotechnol. 2018, 280, 19-30. [CrossRef] [PubMed]

130. Fernandez-Lopez, L.; Pedrero, S.G.; Lopez-Carrobles, N.; Virgen-Ortíz, J.J.; Gorines, B.C.; Otero, C.; Fernandez-Lafuente, R. Physical crosslinking of lipase from Rhizomucor miehei immobilized on octyl agarose via coating with ionic polymers. Process Biochem. 2017, 54, 81-88. [CrossRef]

131. Ji, Q.; Wang, B.; Tan, J.; Zhu, L.; Li, L. Immobilized multienzymatic systems for catalysis of cascade reactions. Process Biochem. 2016, 51, 1193-1203. [CrossRef]

132. Gkantzou, E.; Chatzikonstantinou, A.V.; Fotiadou, R.; Giannakopoulou, A.; Patila, M.; Stamatis, H. Trends in the development of innovative nanobiocatalysts and their application in biocatalytic transformations. Biotechnol. Adv. 2021, 107738. [CrossRef]

133. Giannakopoulou, A.; Gkantzou, E.; Polydera, A.; Stamatis, H. Multienzymatic Nanoassemblies: Recent Progress and Applications. Trends Biotechnol. 2020, 38, 202-216. [CrossRef]

134. Qiu, H.; Li, Y.; Ji, G.; Zhou, G.; Huang, X.; Qu, Y.; Gao, P. Immobilization of lignin peroxidase on nanoporous gold: Enzymatic properties and in situ release of $\mathrm{H}_{2} \mathrm{O}_{2}$ by co-immobilized glucose oxidase. Bioresour. Technol. 2009, 100, 3837-3842. [CrossRef]

135. Mathesh, M.; Liu, J.; Barrow, C.J.; Yang, W. Graphene-Oxide-Based Enzyme Nanoarchitectonics for Substrate Channeling. Chem. A Eur. J. 2017, 23, 304-311. [CrossRef]

136. Gao, F.; Hu, M.; Li, S.; Zhai, Q.; Jiang, Y. Positional orientating co-immobilization of bienzyme CPO/GOx on mesoporous TiO2 thin film for efficient cascade reaction. Bioprocess Biosyst. Eng. 2019, 42, 1065-1075. [CrossRef]

137. Pitzalis, F.; Monduzzi, M.; Salis, A. A bienzymatic biocatalyst constituted by glucose oxidase and Horseradish peroxidase immobilized on ordered mesoporous silica. Microporous Mesoporous Mater. 2017, 241, 145-154. [CrossRef]

138. Rocha-Martin, J.; Velasco-Lozano, S.; Guisán, J.M.; López-Gallego, F. Oxidation of phenolic compounds catalyzed by immobilized multi-enzyme systems with integrated hydrogen peroxide production. Green Chem. 2014, 16, 303-311. [CrossRef]

139. Guisan, J.M.; Bolivar, J.M.; López-Gallego, F.; Rocha-Martín Editors, J. Immobilization of Enzymes and Cells, 4th ed.; In Methods in Molecular Biology; Springer: New York, NY, USA, 2020; ISBN 9781071602140.

140. Cao, L.; Van Rantwijk, F.; Sheldon, R.A. Cross-linked enzyme aggregates: A simple and effective method for the immobilization of penicillin acylase. Org. Lett. 2000, 2, 1361-1364. [CrossRef]

141. Galliani, M.; Santi, M.; Del Grosso, A.; Cecchettini, A.; Santorelli, F.M.; Hofmann, S.L.; Lu, J.Y.; Angella, L.; Cecchini, M.; Signore, G. Cross-Linked Enzyme Aggregates as Versatile Tool for Enzyme Delivery: Application to Polymeric Nanoparticles. Bioconjug. Chem. 2018, 29, 2225-2231. [CrossRef] 
142. Gräslund, S.; Nordlund, P.; Weigelt, J.; Hallberg, B.M.; Bray, J.; Gileadi, O.; Knapp, S.; Oppermann, U.; Arrowsmith, C.; Hui, R.; et al. Protein production and purification. Nat. Methods 2008, 5, 135-146. [CrossRef]

143. Nallamsetty, S.; Waugh, D.S. A generic protocol for the expression and purification of recombinant proteins in Escherichia coli using a combinatorial His6-maltose binding protein fusion tag. Nat. Protoc. 2007, 2, 383-391. [CrossRef]

144. Razib, M.S.M.; Rahman, R.N.Z.R.A.; Shariff, F.M.; Ali, M.S.M. Biochemical and structural characterization of cross-linked enzyme aggregates (Cleas) of organic solvent tolerant protease. Catalysts 2020, 10, 55. [CrossRef]

145. Mafra, A.C.O.; Beltrame, M.B.; Ulrich, L.G.; Giordano, R.D.L.C.; de Arruda Ribeiro, M.P.; Tardioli, P.W. Combined CLEAs of invertase and soy protein for economically feasible conversion of sucrose in a fed-batch reactor. Food Bioprod. Process. 2018, 110, 145-157. [CrossRef]

146. Vaidya, B.K.; Kuwar, S.S.; Golegaonkar, S.B.; Nene, S.N. Preparation of cross-linked enzyme aggregates of 1-aminoacylase via co-aggregation with polyethyleneimine. J. Mol. Catal. B Enzym. 2012, 74, 184-191. [CrossRef]

147. Arsenault, A.; Cabana, H.; Jones, J.P. Laccase-based CLEAs: Chitosan as a novel cross-linking agent. Enzyme Res. $2011,2011$. [CrossRef]

148. Li, X.D.; Wu, J.; Jia, D.C.; Wan, Y.H.; Yang, N.; Qiao, M. Preparation of cross-linked glucoamylase aggregates immobilization by using dextrin and xanthan gum as protecting agents. Catalysts 2016, 6, 77. [CrossRef]

149. Gupta, P.; Dutt, K.; Misra, S.; Raghuwanshi, S.; Saxena, R.K. Characterization of cross-linked immobilized lipase from thermophilic mould Thermomyces lanuginosa using glutaraldehyde. Bioresour. Technol. 2009, 100, 4074-4076. [CrossRef] [PubMed]

150. Paitaid, P.; H-Kittikun, A. Magnetic Cross-Linked Enzyme Aggregates of Aspergillus oryzae ST11 Lipase Using Polyacrylonitrile Coated Magnetic Nanoparticles for Biodiesel Production. Appl. Biochem. Biotechnol. 2020, 190, 1319-1332. [CrossRef]

151. Amaral-Fonseca, M.; Kopp, W.; Giordano, R.D.L.C. Fernández-Lafuente, R.; Tardioli, P.W. Preparation of magnetic cross-linked amyloglucosidase aggregates: Solving some activity problems. Catalysts 2018, 8, 496. [CrossRef]

152. Guimarães, J.R.; de Lima Camargo Giordano, R.; Fernandez-Lafuente, R.; Tardioli, P.W. Evaluation of strategies to produce highly porous cross-linked aggregates of porcine pancreas lipase with magnetic properties. Molecules 2018, 23, 2993. [CrossRef]

153. Diaz-Vidal, T.; Armenta-Perez, V.P.; Rosales-Rivera, L.C.; Mateos-Díaz, J.C.; Rodríguez, J.A. Cross-linked enzyme aggregates of recombinant Candida antarctica lipase B for the efficient synthesis of olvanil, a nonpungent capsaicin analogue. Biotechnol. Prog. 2019, 35, 1-11. [CrossRef]

154. Hernández-García, S.; García-García, M.I.; García-Carmona, F. Improving the production, activity, and stability of CLEAs with diepoxides. Biotechnol. Prog. 2017, 33, 1425-1429. [CrossRef]

155. Velasco-Lozano, S.; López-Gallego, F.; Vázquez-Duhalt, R.; Mateos-Díaz, J.C.; Guisán, J.M.; Favela-Torres, E. Carrier-free immobilization of lipase from candida rugosa with polyethyleneimines by carboxyl-activated cross-linking. Biomacromolecules 2014, 15, 1896-1903. [CrossRef]

156. Goetze, D.; Foletto, E.F.; da Silva, H.B.; Silveira, V.C.C.; Dal Magro, L.; Rodrigues, R.C. Effect of feather meal as proteic feeder on combi-CLEAs preparation for grape juice clarification. Process Biochem. 2017, 62, 122-127. [CrossRef]

157. Tudorache, M.; Gheorghe, A.; Viana, A.S.; Parvulescu, V.I. Biocatalytic epoxidation of $\alpha$-pinene to oxy-derivatives over crosslinked lipase aggregates. J. Mol. Catal. B Enzym. 2016, 134, 9-15. [CrossRef]

158. Li, H.; Wang, R.; Wang, A.; Zhang, J.; Yin, Y.; Pei, X.; Zhang, P. Rapidly and Precisely Cross-Linked Enzymes Using Bio-Orthogonal Chemistry from Cell Lysate for the Synthesis of (S)-1-(2,6-Dichloro-3-fluorophenyl) Ethanol. ACS Sustain. Chem. Eng. 2020, 8, 6466-6478. [CrossRef]

159. Jia, J.; Zhang, W.; Yang, Z.; Yang, X.; Wang, N.; Yu, X. Novel magnetic cross-linked cellulase aggregates with a potential application in lignocellulosic biomass bioconversion. Molecules 2017, 22, 269. [CrossRef]

160. Sheldon, R. CLEAs, Combi-CLEAs and 'Smart' Magnetic CLEAs: Biocatalysis in a Bio-Based Economy. Catalysts 2019,9 , 261. [CrossRef]

161. Dalziel, K. Physical Significance of Michaelis Constants. Nature 1962, 196, 1203-1205. [CrossRef]

162. Yang, T.; Kim, Y.-J.; Roy, J.K.; Kim, Y.-W. Combined Cross-Linked Enzyme Aggregates of Monoamine Oxidase and Putrescine Oxidase as a Bifunctional Biocatalyst for Determination of Biogenic Amines in Foods. Catalysts 2019, 9, 579. [CrossRef]

163. Majewski, M.B.; Howarth, A.J.; Li, P.; Wasielewski, M.R.; Hupp, J.T.; Farha, O.K. Enzyme encapsulation in metal-organic frameworks for applications in catalysis. CrystEngComm 2017, 19, 4082-4091. [CrossRef]

164. McKenna, S.M.; Leimkühler, S.; Herter, S.; Turner, N.J.; Carnell, A.J. Enzyme cascade reactions: Synthesis of furandicarboxylic acid (FDCA) and carboxylic acids using oxidases in tandem. Green Chem. 2015, 17, 3271-3275. [CrossRef]

165. Wu, X.; Ge, J.; Yang, C.; Hou, M.; Liu, Z. Facile synthesis of multiple enzyme-containing metal-organic frameworks in a biomolecule-friendly environment. Chem. Commun. 2015, 51, 13408-13411. [CrossRef]

166. Liang, H.; Jiang, S.; Yuan, Q.; Li, G.; Wang, F.; Zhang, Z.; Liu, J. Co-immobilization of multiple enzymes by metal coordinated nucleotide hydrogel nanofibers: Improved stability and an enzyme cascade for glucose detection. Nanoscale 2016, 8, 6071-6078. [CrossRef]

167. Song, J.; He, W.; Shen, H.; Zhou, Z.; Li, M.; Su, P.; Yang, Y. Exquisitely designed magnetic DNA nanocompartment for enzyme immobilization with adjustable catalytic activity and improved enzymatic assay performance. Chem. Eng. J. 2020, $390,124488$. [CrossRef]

168. Heuson, E.; Froidevaux, R.; Itabaiana, I.; Wojcieszak, R.; Capron, M.; Dumeignil, F. Optimisation of catalysts coupling in multi-catalytic hybrid materials: Perspectives for the next revolution in catalysis. Green Chem. 2021, 23, 1942-1954. [CrossRef] 
169. Engström, K.; Johnston, E.V.; Verho, O.; Gustafson, K.P.J.; Shakeri, M.; Tai, C.-W.; Bäckvall, J.-E. Co-immobilization of an enzyme and a metal into the compartments of mesoporous silica for cooperative tandem catalysis: An artificial metalloenzyme. Angew. Chemie Int. Ed. 2013, 52, 14006-14010. [CrossRef]

170. Magadum, D.B.; Yadav, G.D. Design of tandem catalyst by co-immobilization of metal and enzyme on mesoporous foam for cascaded synthesis of (R)-phenyl ethyl acetate. Biochem. Eng. J. 2018, 129, 96-105. [CrossRef]

171. Magadum, D.B.; Yadav, G.D. One-pot synthesis of (R)-1-(pyridin-4-yl)ethyl acetate using tandem catalyst prepared by coimmobilization of palladium and lipase on mesoporous foam: Optimization and kinetic modeling. Chirality 2017, 29, 811-823. [CrossRef]

172. Moradi, S.; Shokri, Z.; Ghorashi, N.; Navaee, A.; Rostami, A. Design and synthesis of a versatile cooperative catalytic aerobic oxidation system with co-immobilization of palladium nanoparticles and laccase into the cavities of MCF. J. Catal. 2020, 382, 305-319. [CrossRef]

173. Shokri, Z.; Azimi, N.; Moradi, S.; Rostami, A. A novel magnetically separable laccase-mediator catalyst system for the aerobic oxidation of alcohols and 2-substituted-2,3-dihydroquinazolin-4 $(1 \mathrm{H})$-ones under mild conditions. Appl. Organomet. Chem. 2020, 34, e5899. [CrossRef]

174. De Souza, S.P.; Leão, R.A.C.; Bassut, J.F.; Leal, I.C.R.; Wang, S.; Ding, Q.; Li, Y.; Lam, F.L.-Y.; de Souza, R.O.M.A.; Itabaiana, I., Jr. New Biosilified Pd-lipase hybrid biocatalysts for dynamic resolution of amines. Tetrahedron Lett. 2017, 58, 4849-4854. [CrossRef]

175. Zhang, X.; Jing, L.; Chang, F.; Chen, S.; Yang, H.; Yang, Q. Positional immobilization of Pd nanoparticles and enzymes in hierarchical yolk-shell@shell nanoreactors for tandem catalysis. Chem. Commun. 2017, 53, 7780-7783. [CrossRef] [PubMed]

176. Zhang, N.; Hübner, R.; Wang, Y.; Zhang, E.; Zhou, Y.; Dong, S.; Wu, C. Surface-Functionalized Mesoporous Nanoparticles as Heterogeneous Supports to Transfer Bifunctional Catalysts into Organic Solvents for Tandem Catalysis. ACS Appl. Nano Mater. 2018, 1, 6378-6386. [CrossRef]

177. Ferraz, C.A.; do Nascimento, M.A.; Almeida, R.F.O.; Sergio, G.G.; Junior, A.A.T.; Dalmônico, G.; Caraballo, R.; Finotelli, P.V.; Leão, R.A.C.; Wojcieszak, R.; et al. Synthesis and characterization of a magnetic hybrid catalyst containing lipase and palladium and its application on the dynamic kinetic resolution of amines. Mol. Catal. 2020, 493, 111106. [CrossRef]

178. Gao, L.; Wang, Z.; Liu, Y.; Liu, P.; Gao, S.; Gao, J.; Jiang, Y. Co-immobilization of metal and enzyme into hydrophobic nanopores for highly improved chemoenzymatic asymmetric synthesis. Chem. Commun. 2020, 56, 13547-13550. [CrossRef] [PubMed]

179. Gao, S.; Wang, Z.; Ma, L.; Liu, Y.; Gao, J.; Jiang, Y. Mesoporous Core-Shell Nanostructures Bridging Metal and Biocatalyst for Highly Efficient Cascade Reactions. ACS Catal. 2020, 10, 1375-1380. [CrossRef]

180. Wang, Y.; Zhang, N.; Zhang, E.; Han, Y.; Qi, Z.; Ansorge-Schumacher, M.B.; Ge, Y.; Wu, C. Heterogeneous Metal-OrganicFramework-Based Biohybrid Catalysts for Cascade Reactions in Organic Solvent. Chem. A Eur. J. 2019, 25, 1716-1721. [CrossRef]

181. Wu, Y.; Shi, J.; Mei, S.; Katimba, H.A.; Sun, Y.; Wang, X.; Liang, K.; Jiang, Z. Concerted Chemoenzymatic Synthesis of $\alpha$-Keto Acid through Compartmentalizing and Channeling of Metal-Organic Frameworks. ACS Catal. 2020, 10, 9664-9673. [CrossRef]

182. Dutta, S.; Kumari, N.; Dubbu, S.; Jang, S.W.; Kumar, A.; Ohtsu, H.; Kim, J.; Cho, S.H.; Kawano, M.; Lee, I.S. Highly Mesoporous Metal-Organic Frameworks as Synergistic Multimodal Catalytic Platforms for Divergent Cascade Reactions. Angew. Chemie 2020, 132, 3444-3450. [CrossRef]

183. Xia, H.; Li, Z.; Zhong, X.; Li, B.; Jiang, Y.; Jiang, Y. HKUST-1 catalyzed efficient in situ regeneration of NAD+ for dehydrogenase mediated oxidation. Chem. Eng. Sci. 2019, 203, 43-53. [CrossRef]

184. Li, H.; Qiu, C.; Cao, X.; Lu, Y.; Li, G.; He, X.; Lu, Q.; Chen, K.; Ouyang, P.; Tan, W. Artificial Nanometalloenzymes for Cooperative Tandem Catalysis. ACS Appl. Mater. Interfaces 2019, 11, 15718-15726. [CrossRef] [PubMed]

185. Wang, Y.; Zhang, N.; Hübner, R.; Tan, D.; Löffler, M.; Facsko, S.; Zhang, E.; Ge, Y.; Qi, Z.; Wu, C. Enzymes Immobilized on Carbon Nitride (C 3 N 4) Cooperating with Metal Nanoparticles for Cascade Catalysis. Adv. Mater. Interfaces 2019, 6, 1801664. [CrossRef]

186. Reetz, M.T.; Schimossek, K. Lipase-catalyzed dynamic kinetic resolution of chiral amines: Use of palladium as the racemization catalyst. Chim. Int. J. Chem. 1996, 50, 668-669.

187. Shakeri, M.; Tai, C.; Göthelid, E.; Oscarsson, S.; Bäckvall, J.-E. Small Pd nanoparticles supported in large pores of mesocellular foam: An excellent catalyst for racemization of amines. Chem. A Eur. J. 2011, 17, 13269-13273. [CrossRef] [PubMed] 